\title{
A Peroxidase Peroxiredoxin 1-Specific Redox Regulation of the Novel FOXO3 microRNA Target let-7
}

\author{
Barbara L. Hopkins, ${ }^{1,2, *}$ Monica Nadler, ${ }^{3, *}$ John J. Skoko,,* Thierry Bertomeu, Andrea Pelosi, \\ Parisa Mousavi Shafaei, Kevin Levine, Anja Schempf, Bodvael Pennarun, Bo Yang, Dipak Datta, \\ Octavian Bucur, ${ }^{3,6}$ Kenneth Ndebele, ${ }^{3}$ Steffi Oesterreich,2 Da Yang, Maria Giulia Rizzo, \\ Roya Khosravi-Far, and Carola A. Neumann ${ }^{2}$
}

\begin{abstract}
Precision in redox signaling is attained through posttranslational protein modifications such as oxidation of protein thiols. The peroxidase peroxiredoxin 1 (PRDX1) regulates signal transduction through changes in thiol oxidation of its cysteines. We demonstrate here that PRDX1 is a binding partner for the tumor suppressive transcription factor FOXO3 that directly regulates the FOXO3 stress response. Heightened oxidative stress evokes formation of disulfide-bound heterotrimers linking dimeric PRDX1 to monomeric FOXO3. Absence of PRDX1 enhances FOXO3 nuclear localization and transcription that are dependent on the presence of Cys31 or Cys150 within FOXO3. Notably, FOXO3-T32 phosphorylation is constitutively enhanced in these mutants, but nuclear translocation of mutant FOXO3 is restored with PI3K inhibition. Here we show that on $\mathrm{H}_{2} \mathrm{O}_{2}$ exposure, transcription of tumor suppressive miRNAs let-7b and let-7c is regulated by FOXO3 or PRDX1 expression levels and that let-7c is a novel target for FOXO3. Conjointly, inhibition of let-7 microRNAs increases let-7-phenotypes in PRDX1-deficient breast cancer cells. Altogether, these data ascertain the existence of an $\mathrm{H}_{2} \mathrm{O}_{2}$-sensitive PRDX1-FOXO3 signaling axis that fine tunes FOXO3 activity toward the transcription of gene targets in response to oxidative stress. Antioxid. Redox Signal. 28, 62-77.
\end{abstract}

Keywords: FOXO3, PRDX1, let-7, oxidative stress, breast cancer, tumor suppressor

\section{Introduction}

A PPROPRIATE CELL RESPONSES to stress are necessary to decide cell fate. Recent evidence establishes protein sulfhydryl groups as modulators of signaling events through oxidation state changes, which impact protein interactions and activity (15). This posttranslational calibration requires a dynamic reversibility of the protein modification. Interestingly, in contrast to (de)/phosphorylation events induced by the interplay of protein kinases and phosphatases, protein

\footnotetext{
${ }^{1}$ Department of Human Genetics, Graduate School of Public Health, University of Pittsburgh, Pittsburgh, Pennsylvania.

${ }^{2}$ Department of Pharmacology and Chemical Biology, Magee Womens Research Institute, University of Pittsburgh Cancer Institute, Pittsburgh, Pennsylvania.

${ }^{3}$ Department of Pathology, Harvard Medical School and Beth Israel Deaconess Medical Center, Boston, Massachusetts.

${ }^{4}$ Oncogenomic and Epigenetic Unit, Department of Research, Advanced Diagnostics and Technological Innovation, Translational Research Area Regina Elena National Cancer Institute, Rome, Italy.

${ }^{5}$ Department of Pharmaceutical Sciences, University of Pittsburgh, Pittsburgh, Pennsylvania.

${ }^{6}$ Institute of Biochemistry of the Romanian Academy, Bucharest, Romania.

*These authors contributed equally to this work.
}

Post-acceptance note by corresponding author: After careful consideration and new information obtained from Dr. Roya KoshraviFar, I request that Dr. Ndebele and Dr. Bucur be included as co-authors to acknowledge their intellectual and experimental contributions while in the former laboratory of Dr. Khosravi-Far. Robin Zaboulian will be included in the acknowledgement for technical help. I regret that I did not inform Dr. Khosravi-Far of the author omissions before the manuscript was submitted to ARS. However, the scientific writeup is unchanged compared to a former submission that Dr. Khosravi-Far had seen and agreed upon. Please note that I fully vouch for the validity of the data generated in my laboratory and shown in the manuscript accepted by ARS.

(C) Barbara L. Hopkins, et al., 2017; Published by Mary Ann Liebert, Inc. This article is available under the Creative Commons License CCBY-NC (http://creativecommons.org/licenses/by-nc/4.0). This license permits non-commercial use, distribution and reproduction in any medium, provided the original work is properly cited. Permission only needs to be obtained for commercial use and can be done via RightsLink. 


\section{Innovation}

It is widely established that free radicals such as $\mathrm{H}_{2} \mathrm{O}_{2}$ cause oxidative stress and promote disease. Members of the mammalian forkhead (FOXO) family of transcription factors are tumor suppressors that oppose oxidative stress, but the mechanisms by which FOXOs sense and respond to oxidative stress are not well understood. Peroxiredoxins are $\mathrm{H}_{2} \mathrm{O}_{2}$ scavenger proteins that destroy peroxides. Herein, we show that peroxiredoxin 1 (PRDX1) directly binds to FOXO3 in a peroxide dependent fashion, which in turn regulates FOXO activity differently toward proapoptotic and antioxidant response genes. These findings are highly significant as they reveal an oxidative stresssensitive FOXO-PRDX1 signaling pathway that calibrates FOXO responses in tumor suppression and aging toward the regulated expression of genetic and epigenetic factors when PRDX1 detects increased cellular peroxide levels.

sulfhydryl group oxidation to highly oxidized forms such as sulfonic acid can be irreversible, resulting in protein degradation or in the case of peroxiredoxins, a change of function. Peroxiredoxin (PRDX) family members (typical 2-Cys: PRDX1-4, atypical 2-Cys: PRDX5, and 1-Cys: PRDX6) are antioxidant enzymes that reduce peroxides via catalytic cysteine oxidation to sulfenic acid. Evidence is accumulating that demonstrates 2-Cys PRDXs as important redox sensors in signaling (36) through two unique features: (a) a highly reactive catalytic cysteine that converts to a protein sulfenic acid moiety that produces a disulfide bond with a resolving cysteine, which can be reduced via thioredoxin to reset catalytic function (22); and (b) during recycling the catalytic cysteine of PRDX can be further oxidized, which promotes formation of PRDX decamers that display chaperone functionality, but lack peroxidase activity (36). These features equip PRDX1 to sense and react to changes in redox signaling accordingly by controlling protein-binding partners. For example, we have recently shown heightened oxidative stress can over-oxidize PRDX1, which causes PRDX1 to dissociate from MKP1 as well as increase association and activity of MKP5, thereby regulating senescence (61). A similar mechanism has been described for PRDX1 and PTEN (9) or MST1 (35) and for PRDX2 and ERp46 (41). Recently, PRDXs have gained attention to act as redox relays involving the catalytic and resolving cysteine to form disulfides with the partnering protein to transfer oxidative equivalents. This has been suggested for PRDX1 and $\operatorname{ASK} 1(28,30)$ and most recently, a transient PRDX2-STAT3 redox relay has been described that resulted in STAT3 oligomerization and inactivation (57).

Our studies shown here demonstrate that PRDX1 interacts with the transcription factor FOXO3 through disulfide bonds. The mammalian forkhead box transcription factors of the O class (FOXOs) comprise four family members (FOXO1, 3, 4, and 6), which are highly related tumor suppressors that provide resistance to oxidative stress, halt cell cycle progression, and control the induction of cellular apoptosis. Although FOXOs serve as major cellular reactive oxygen species (ROS) arbitrators (45), the mechanisms by which FOXOs sense and integrate ROS signals to define transcriptional outcomes are still poorly understood (17). A recent mass spectrometry analysis indicated FOXO cysteines to be involved in protein binding, underscoring their role for redox sensing (46). In response to oxidative stress, FOXO proteins translocate to the nucleus due to phosphorylation by mammalian sterile 20-like kinase 1 (MST1) and Jun N-terminal kinase (JNK), as well as monoubiquitination (7). FOXO is negatively regulated through the phosphoinositide 3-kinase (PI3K)/AKT signaling pathway, which promotes cytoplasmic sequestration of FOXO via AKT-induced phosphorylation and therefore causing FOXO inactivation in many cancers $(7,62)$.

As cancer cells carry a higher pro-oxidant burden compared to normal cells (32), we examined the role of PRDX1 in FOXO3 function and binding under pro-oxidant conditions. We establish that PRDX1 binds FOXO3 under $\mathrm{H}_{2} \mathrm{O}_{2}$ stress and regulates $\mathrm{FOXO} 3$ nuclear localization and activity through disulfide bridges involving the PRDX1 peroxidatic C52 and resolving $\mathrm{C} 173$ and surprisingly C71, which has not been previously seen. Within FOXO3, PRDX1 binding engages C31 and 150, the latter of which is not conserved among FOXO family members. Mutation of these FOXO3 cysteines causes changes to the phosphorylation levels of AKT substrate sites and heightened cytoplasmic localization that is responsive to $\mathrm{PI} 3 \mathrm{~K}$ inhibition in comparison to FOXO3WT. We also demonstrate for the first time that let-7c, a member of the let-7 family widely regarded as a tumor suppressor microRNA (miRNA), is a novel FOXO3 target. let-7c and let-7b miRNAs are significantly increased by $\mathrm{H}_{2} \mathrm{O}_{2}$ exposure in a FOXO3- and PRDX1-dependent manner, and inhibit breast cancer cell migration. Notably, several

FIG. 1. PRDX1 binds to FOXO3 in an $\mathrm{H}_{2} \mathrm{O}_{2}$ dose-dependent manner and regulates FOXO3 nuclear localization. (A) Immunoprecipitation of precleared lysate with PRDX1 or IgG antibodies found PRDX1 bound FOXO3. 293T cells underwent serum starvation for $30 \mathrm{~min}$ and were then treated with the 0 or $100 \mu M \mathrm{H}_{2} \mathrm{O}_{2}$ for an additional 30 min. (B and $\mathbf{C}$ ) $293 \mathrm{~T}$ cells were transfected with pcDNA3-FLAG-FOXO3A or EV and treated with increasing concentrations of $\mathrm{H}_{2} \mathrm{O}_{2}$ for the indicated times. Before lysis, cells were washed with $20 \mathrm{~m} M$ NEM in phosphate-buffered saline to block lysis-induced disulfide bond formation. FLAG-labeled proteins were immunoprecipitated and detected by immunoblot with FLAG and PRDX1 antibodies. (D and E) The percentage of 293T cells displaying nuclear FOXO3-EGFP localization was enhanced with reduction of PRDX1; 150 or more cells analyzed per sample, $p<0.0001$ ( $t$-test). Cells infected with shPRDX1A or control lentivirus for $48 \mathrm{~h}$, followed by transfection with FOXO3-EGFP for $24 \mathrm{~h} . \mathrm{H}_{2} \mathrm{O}_{2}$ was added during the last 30 min. (F) HA-PRDX reduced FLAG-FOXO3 activity when transiently cotransfected into MEF and analyzed utilizing a dualluciferase reporter assay. Values (mean $+\mathrm{SE})$ were normalized to vehicle treatment. $* p<0.05, t$-test $(N=3)$. (G) qPCR gene transcription of SESN3 and P27 was increased in PRDX1-deficient 293T cells (white bars) treated with $250 \mu M \mathrm{H}_{2} \mathrm{O}_{2}$ compared to pLKO.1 control cells (black bars) after $16 \mathrm{~h}$. Values (mean $+\mathrm{SE}$ ) were normalized to vehicle treatment. $* p<0.05, t$-test $(N=3)$. MEF, murine embryonic fibroblast; NEM, $N$-ethylmaleimide; SE, standard error. 
A

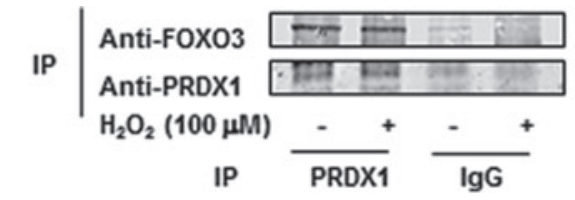

Lysate $\mid \begin{aligned} & \text { Anti-FOXO3 } \\ & \text { Anti-PRDX1 } \\ & \text { Anti-Actin } \\ & \mathrm{H}_{2} \mathrm{O}_{2}(100 \mu \mathrm{M})-\end{aligned}$
B
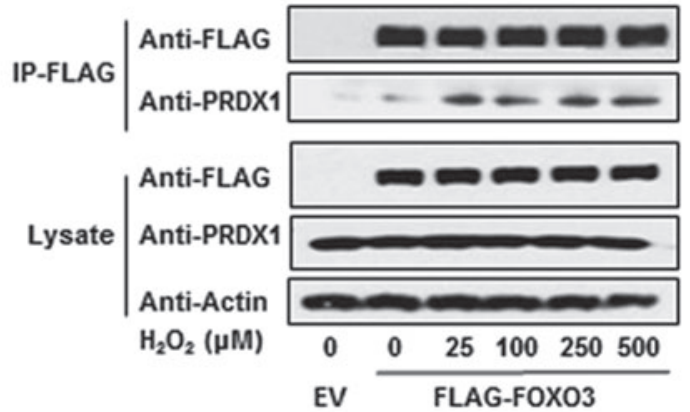

C
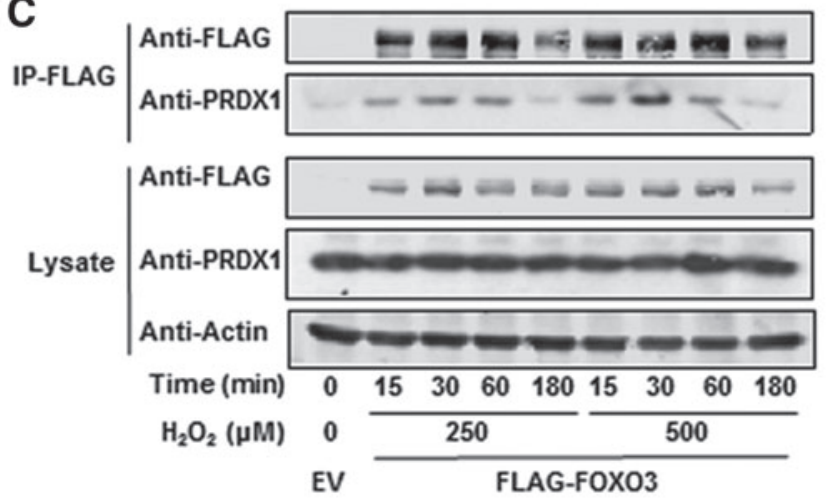

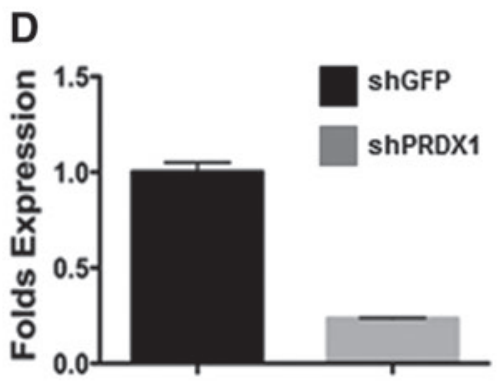

$\mathrm{H}_{2} \mathrm{O}_{2} \mathrm{O} \mu \mathrm{M}$

E
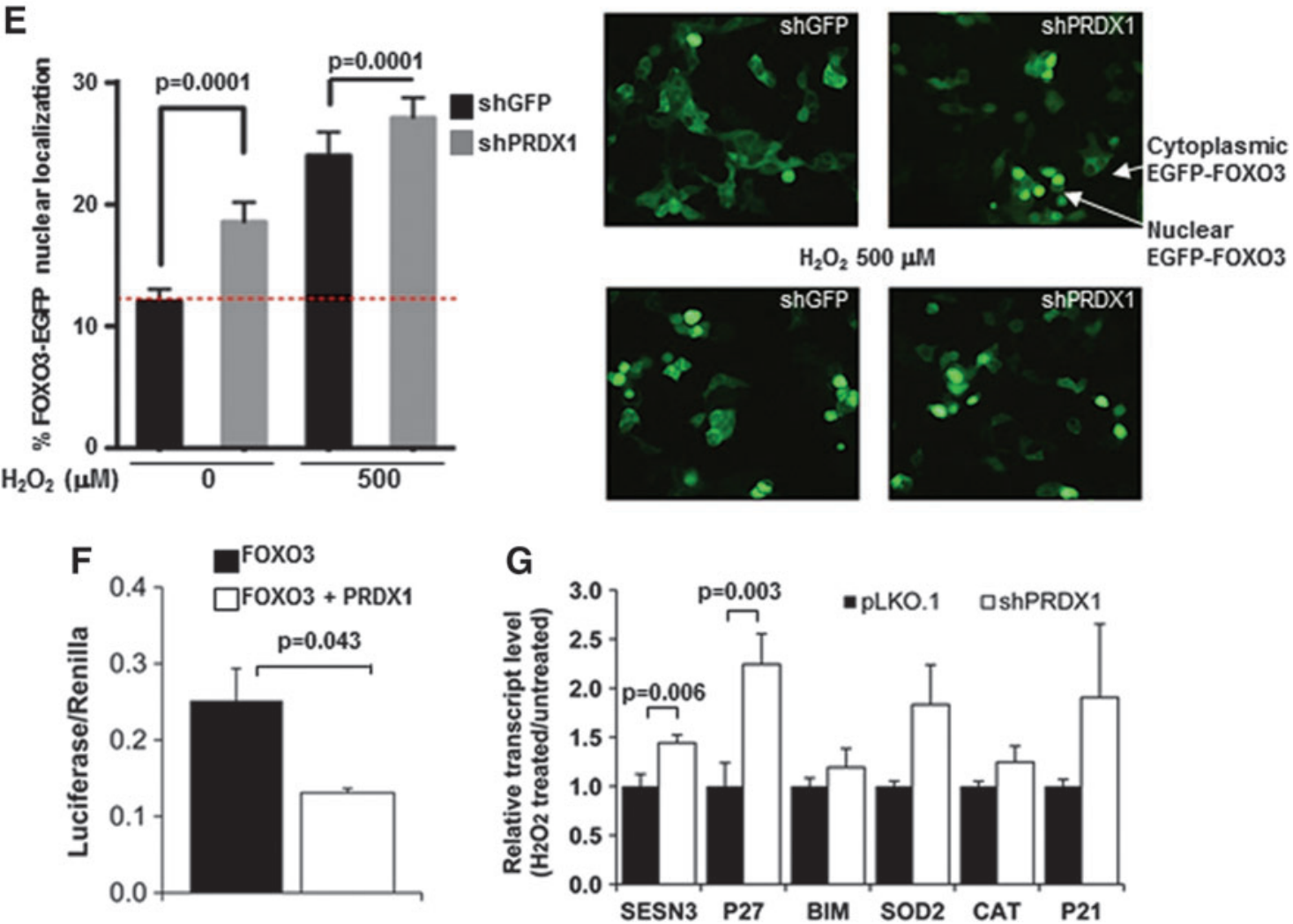

functional and mechanistic parallels exist for FOXO proteins and let-7. Both mediate tumor suppression and glucose homeostasis (60), and expression of the let-7 miRNA family has similarly been shown to be governed by various ROSinducing stressors $(52,53)$. Importantly, loss of let-7c ex- pression in cancer cells promotes migration and invasion $(33,66)$. Taken together, these data provide compelling evidence for an existence of a redox-specific signaling axis comprising PRDX1, FOXO3, and let-7c miRNAs in regulating oxidative stress signaling in breast cancer. 


\section{Results}

\section{PRDX1 interacts with FOXO3 and regulates} its nuclear function

We confirmed a PRDX1 FOXO3 interaction by precipitating endogenous FOXO3 bound to PRDX1 by immunoblot (Fig. 1A and Supplementary Slide S1A; Supplementary Data are available online at www.liebertpub.com/ars). Precipitation of FLAG-FOXO3 from transfected 293T cells indicated that PRDX1 binding was elevated following treatment with 25-500 $\mu M \mathrm{H}_{2} \mathrm{O}_{2}$ in the presence of lysis buffer containing $\mathrm{N}$-ethylmaleimide (NEM), a chemical agent that alkylates the thiol group on cysteines, therefore reducing postlysis oxidation events that might otherwise occur (Fig. 1B and Supplementary Slide S1B). Interestingly, the PRDX1-FOXO3 complex displayed time-dependent binding dynamics when transfected $293 \mathrm{~T}$ cells were treated with 250 and $500 \mu \mathrm{M}$ $\mathrm{H}_{2} \mathrm{O}_{2}$ (Fig. 1C and Supplementary Slide S1C). Maximal PRDX1-FOXO3 oligomerization was seen at $30 \mathrm{~min}$, which returned to baseline after $3 \mathrm{~h}$. An assay to measure apoptosis, cell viability, and cytotoxicity found no significant changes in any of the three measurements, between treatment and no treatment over a period of $3 \mathrm{~h}$, suggesting that the decrease in PRDX1-FOXO3 binding was not a result of cell death (Supplementary Fig. S1B). Further experiments in the absence of NEM found that binding dynamics of FLAGFOXO3 and PRDX1 followed a U-shaped $\mathrm{H}_{2} \mathrm{O}_{2}$ dose curve with maximal binding at $100 \mu M \mathrm{H}_{2} \mathrm{O}_{2}$ and complex dissociation at higher concentrations (Supplementary Fig. S1A and Supplementary Slide S1A). In addition, we could not detect any over-oxidized PRDX1 binding to FOXO3, suggesting that PRDX1 over-oxidation on its catalytic cysteine may induce FOXO3 release (Supplementary Fig. S1A and Supplementary Slide S1A).

To investigate if PRDX1 binding to FOXO3 has a functional impact, we assessed FOXO3 nuclear translocation in $\operatorname{Prd} x 1^{-/-}$and $\operatorname{Prd} x 1^{+/+}$murine embryonic fibroblasts (MEFs). Interestingly, MEFs lacking PRDX1 displayed primarily nuclear FOXO3 localization in contrast to wild-type MEFs expressing PRDX1 (Supplementary Fig. S1C). Given the low transfection efficiency of MEFs, we next utilized 293T cells with reduced PRDX1 expression transfected with a FOXO3EGFP reporter construct (Fig. 1D, Supplementary Fig. S1D and Supplementary Slide S1D). As Figure 1E shows, FOXO3 nuclear localization was significantly increased in $293 \mathrm{~T}$ cells harboring 90\% less PRDX1, suggesting PRDX1 deterred FOXO3 nuclear translocation. Investigating the role of PRDX1 on FOXO3 function further, we next evaluated FOXO3 activity specifically using a dual-luciferase reporter assay in $P r d x 1^{-1}$ MEFs transiently transfected with FOXO3 and/or PRDX1. As expected, PRDX1 decreased luciferase signals by $50 \%$ (Fig. 1F). Investigating FOXO3 target gene expression by quantitative polymerase chain reaction (qPCR) showed that PRDX1 knockdown increased expression of several FOXO3 targets in $\mathrm{H}_{2} \mathrm{O}_{2}$-treated $293 \mathrm{~T}$ cells compared to control, where SESN3 and P27 differences were significantly enhanced (Fig. 1G).

\section{PRDX1 and FOXO3 associate through disulfide bonds}

2-Cys peroxiredoxins and FOXO proteins have been suggested to form disulfide bonds with target proteins (46). We explored whether covalent cysteine disulfide bridges exist between PRDX1 and FOXO3. Five cysteines are present in FOXO3 at positions $31,150,190,362$, and 622, while PRDX1 has four cysteines at positions 52, 71, 83, and 173 (Fig. 2A). To investigate possible disulfide bridge interactions between PRDX1 and FOXO3, we analyzed $\operatorname{PrdxI^{+/+}}$ and $\operatorname{Prd} x 1^{-/}$MEFs using two-color infrared (IR) antibody detection and identified one band staining positive for both PRDX1 and FOXO3 around $140 \mathrm{kDa}$ after $\mathrm{H}_{2} \mathrm{O}_{2}$ treatment (Fig. 2B), which was reduced when lysates were treated with $\beta$-ME (Supplementary Fig. S2A). This suggests an oligomeric PRDX1-FOXO3 protein complex composed of monomeric FOXO3 (90 kDa) disulfide bound to dimeric PRDX1 $(2 \times 23 \mathrm{kDa})$. To gain further insight into the specific cysteines responsible for the PRDX1-FOXO3 interaction, coimmunoprecipitations (co-IPs) of endogenous PRDX1 with FLAG-FOXO3 single cysteine mutants revealed that loss of FOXO3 C31 or C150 decreased binding to PRDX1 (Fig. 2C and Supplementary Slide S2C). Conversely, coprecipitating endogenous FOXO3 with HA-PRDX1 single cysteine mutants showed that PRDX1 C52, C71, or C173 mutants decreased binding of endogenous FOXO3 as well (Fig. 2D and Supplementary Slide S2D). PRDX1 C71 is yet to be described to play a role in PRDX1 protein associations. In addition, disulfide-dependent complex formation was further analyzed and demonstrated that, as shown in Figure 2C, while $\mathrm{H}_{2} \mathrm{O}_{2}$ treatment induced endogenous PRDX1 binding to wild-type FLAG-FOXO3, and decreased PRDX1 binding to C31 and C150 single mutants, the FLAG-FOXO3 double mutant

FIG. 2. PRDX1 and FOXO3 form disulfide bonds. (A) Domain structures of FOXO3 and PRDX1 proteins. (B) A PRDX1-FOXO3 complex was detected under nonreducing conditions in $\operatorname{Prdx} 1^{+/+}$, but not $\operatorname{Prdx1^{-/-}}$ MEFs, when treated with the indicated concentrations of $\mathrm{H}_{2} \mathrm{O}_{2}$ for $30 \mathrm{~min}$ by immunoblot with two-color IR antibody detection. (C) Anti-FLAG IP of 293T cells transfected with EV or FLAG-FOXO3 (WT or single C-to-S mutants) displayed reduced PRDX1 binding to FOXO3 C31S or C150S when treated with $\mathrm{H}_{2} \mathrm{O}_{2}$ for 30 min by immunoblot. (D) Anti-HA IP of 293T cells transfected with EV or HA-PRDX1 (WT or C-to-S mutants) showed reduced FOXO3 binding with PRDX1 C52S, C71S, or C173S mutants when treated with $\mathrm{H}_{2} \mathrm{O}_{2}$ for $30 \mathrm{~min}$ (*HA-PRDX1). (E) Mutation of FOXO3 cysteines reduced PRDX1 binding when treated with $25 \mu M \mathrm{H}_{2} \mathrm{O}_{2}$ for $30 \mathrm{~min}$. Anti-FLAG IP of 293T cells transfected with EV or FLAG-FOXO3 (WT, C31S, C150S, C31, 150S double mutant, or $\Delta$ Cys mutants) was detected by immunoblot. (F) A PRDX1-FOXO3 complex was detected in FLAG-FOXO3 WT, but not C31S or C150S mutant Anti-FLAG samples under nonreducing conditions in 293T cells cotransfected with FLAG-FOXO3 constructs and HA-PRDX1 treated with $25 \mu M \mathrm{H}_{2} \mathrm{O}_{2}$ for 30 min. (G-I) The ability of PRDX1 to reduce FOXO3 activity was inhibited with $\mathrm{H}_{2} \mathrm{O}_{2}$ treatment in 293T cells in FOXO3 WT, but not C31S or C150S mutants. Cells were transiently transfected with FOXO3 and PRDX1 constructs in a dual-luciferase assay treated with $0-250 \mu M \mathrm{H}_{2} \mathrm{O}_{2}$. Values (mean $+\mathrm{SE}$ ) were normalized to FOXO3 vehicle treatment. ${ }^{*} p<0.05, t$-test $(N=3)$. NES, nuclear export sequence; NLS, nuclear localization signal. 
A

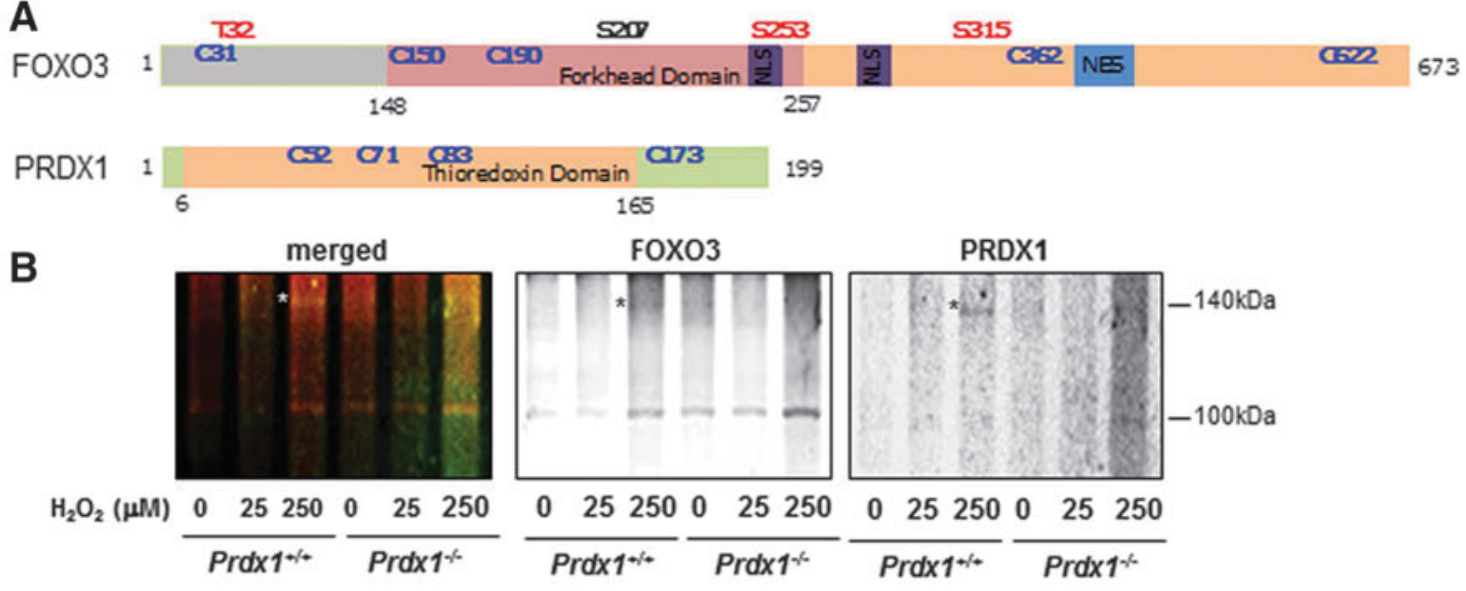

C

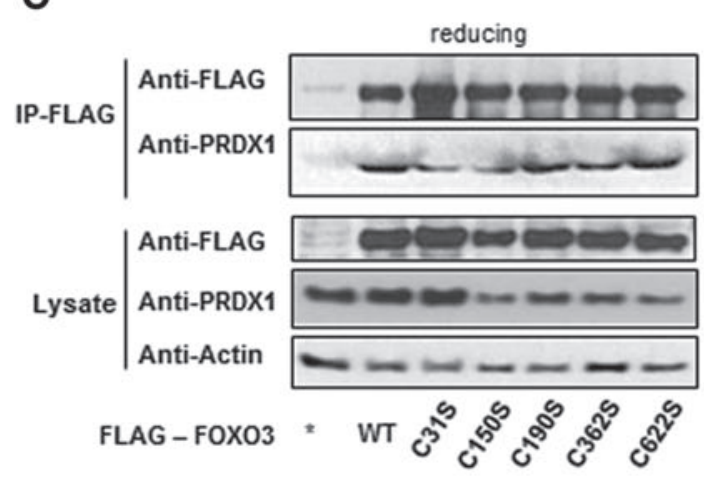

E
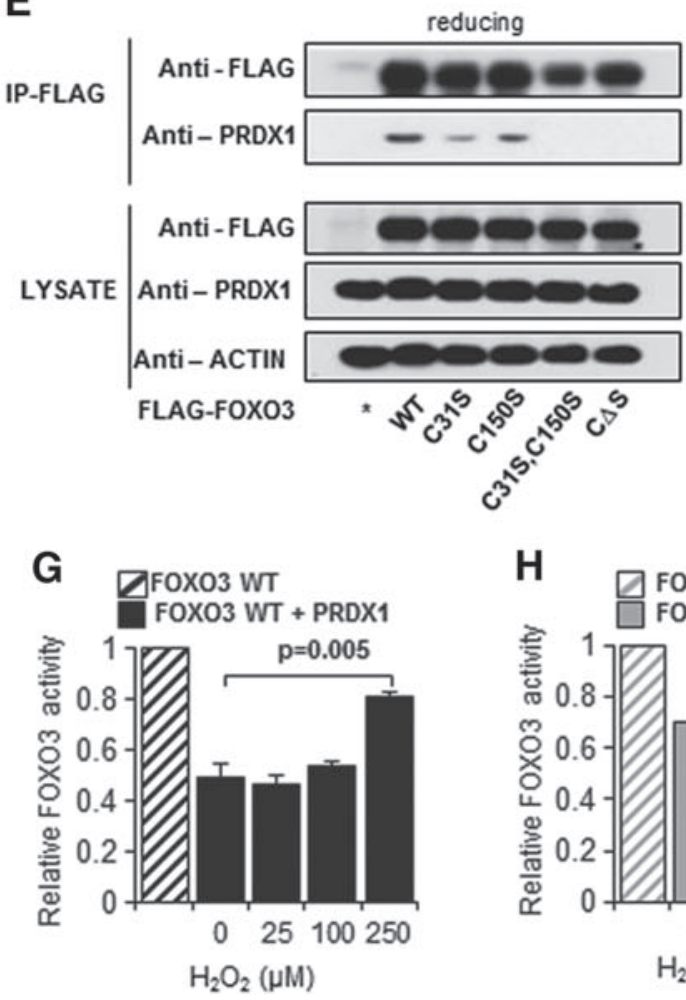

D
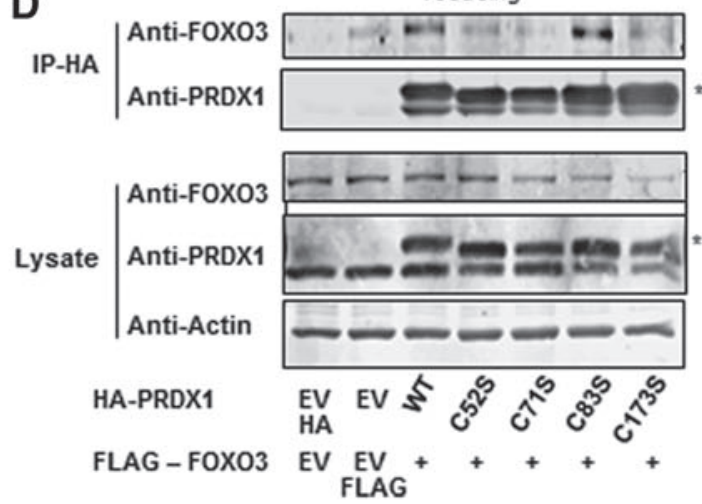

F
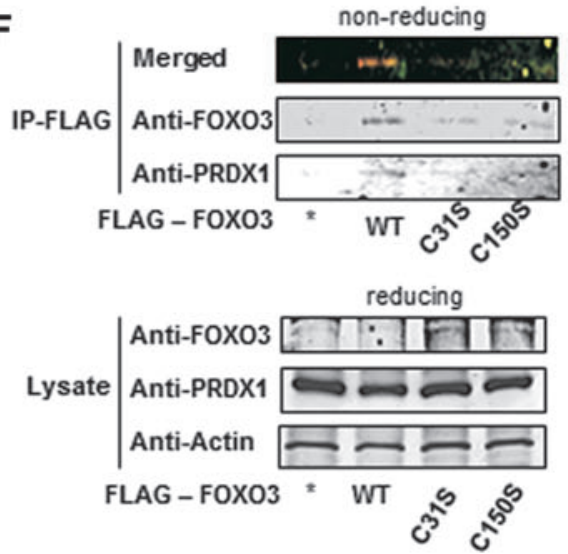

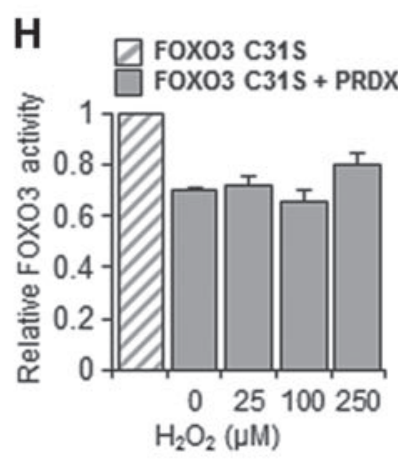

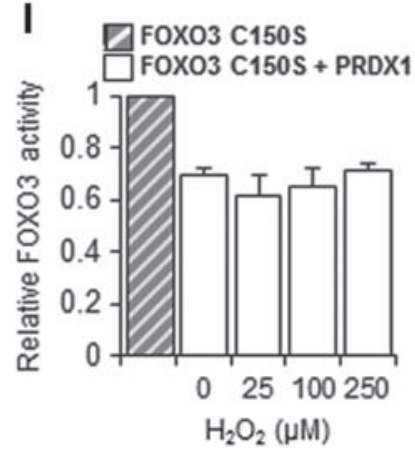



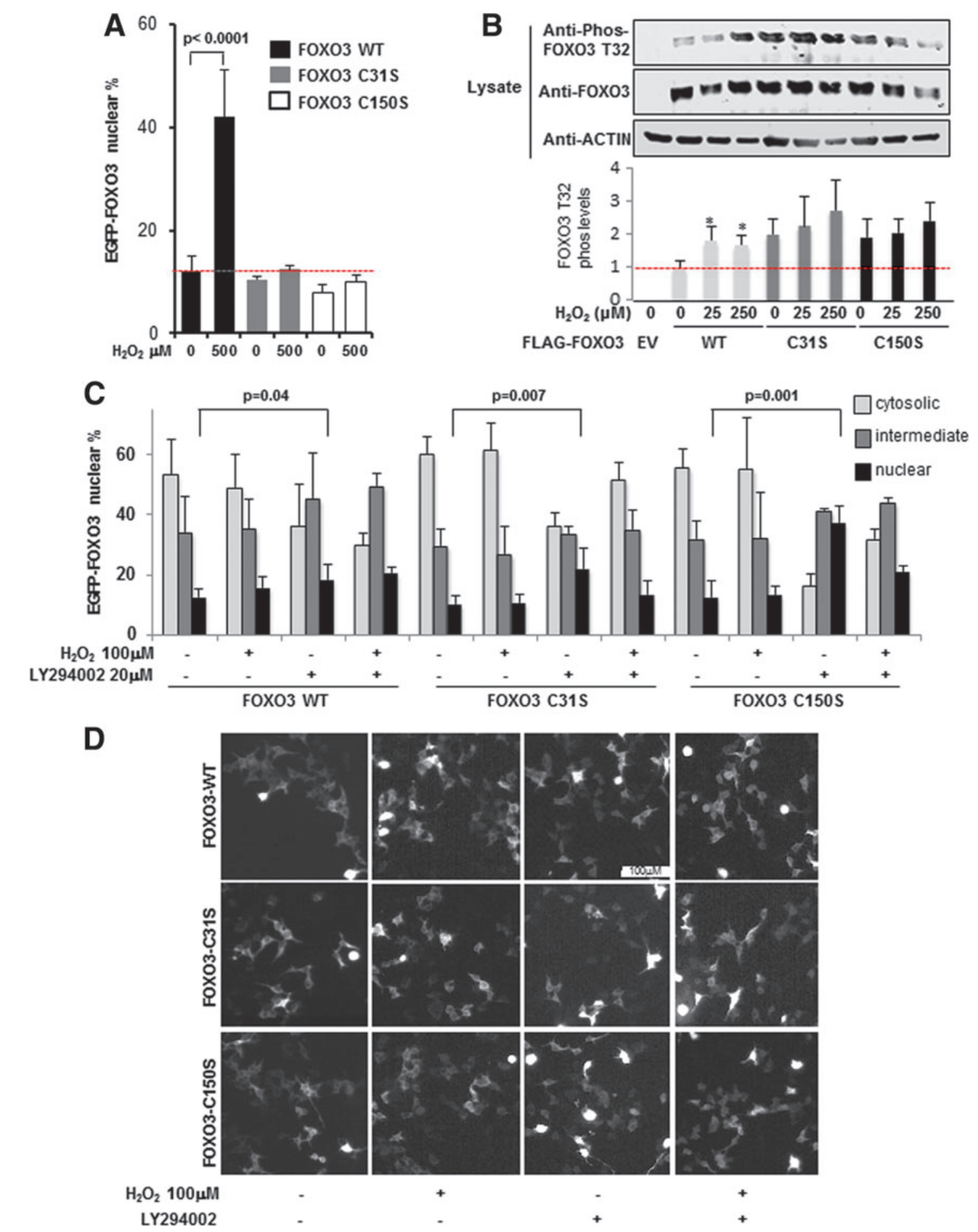

FIG. 3. Interdisulfides between PRDX1 and FOXO3 modulate FOXO3 subcellular localization and FOXO3 phosphorylation. (A) Thirty minutes of $\mathrm{H}_{2} \mathrm{O}_{2}$ treatment enhanced nuclear EGFP-FOXO3 content in WT, but not C31 or C150 mutant constructs, $48 \mathrm{~h}$ following transfection in 293T cells. Percentage of cells displaying nuclear FOXO3-EGFP localization is indicated. (B) T32 phosphorylation of FOXO3 C31S or C150S was heightened under basal conditions compared to FOXO3 WT. 293 cells transfected with FLAG-FOXO3 (WT, C31, or C150 mutants) were treated with $\mathrm{H}_{2} \mathrm{O}_{2}$ and detected by immunoblot for FOXO3 Phospho-T32, FOXO3, and Actin. Phospho-T32 signals were normalized to total FOXO3. Values represent mean + SD normalized to WT $0 \mu M \mathrm{H}_{2} \mathrm{O}_{2}$. ${ }^{*} p<0.05(N=3)$. (C) PI3K inhibition with $20 \mu M$ LY294002 enhanced nuclear FOXO3-EGFP WT, C1S, or C2S mutants in transiently transfected 293T cells after $24 \mathrm{~h}$. Values represent mean $+\mathrm{SE}(N=3)$ with $150-400$ cells counted per sample by fluorescence microscopy. Experiment was repeated twice. (D) Representative pictures of (C). 
(C31,150S), and the quintuple cysteine to serine mutant FLAG-FOXO3 (CAS) showed no PRDX1 binding (Fig. 2E and Supplementary Slide S2E). To further examine the importance of FOXO3 $\mathrm{C} 31$ and $\mathrm{C} 150$ in oligomeric formation, we expressed FLAG-FOXO3WT, C31S, and C150S in 293T cells. Figure 2F (Supplementary Slide S2F) shows that the FOXO3-PRDX1 oligomer can be detected with wild-type FLAG-FOXO3, but not with single cysteine FOXO3 mutants. As FOXO3C31 and FOXOC150 are important for PRDX1 binding, we next examined how cysteine mutant FOXO3 activities were responding to PRDX1-mediated decrease under $\mathrm{H}_{2} \mathrm{O}_{2}$-induced stress. Using a dual-luciferase reporter assay, we observed that under lower $\mathrm{H}_{2} \mathrm{O}_{2}$ treatments PRDX1 is able to decrease FOXO3 activity significantly, and under higher $\mathrm{H}_{2} \mathrm{O}_{2}$ doses $(250 \mu M)$, PRDX1-induced decrease of FOXO3 was abrogated (Fig. 2G). In addition, PRDX1 did not further decrease FOXO3 $\mathrm{C} 31$ or $\mathrm{C} 150$ activity, nor did higher $\mathrm{H}_{2} \mathrm{O}_{2}$ doses increase mutant activity (Fig. $2 \mathrm{H}, \mathrm{I}$ ). In contrast to wild-type FOXO3, PRDX1 was unable to lower FOXO3 $(\Delta \mathrm{C})$ luciferase activity (Supplementary Fig. S2B).

\section{FOXO3 disulfide bonding with PRDX1 determines subcellular localization under $\mathrm{H}_{2} \mathrm{O}_{2}$ stress}

Several lines of evidence demonstrate that FOXO proteins translocate to the nucleus under increased levels of ROS, reviewed in Ref. (16). Importantly, nuclear localization of FOXO proteins is a prerequisite for their transcriptional activity, as such FOXOs are highly regulated through mechanisms that alter nucleocytoplasmic shuttling (17). To address if the PRDX1-FOXO3 disulfide bound complex influences FOXO3 protein nuclear localization, we expressed WT-,
C31S-, or C150S-FOXO3-EGFP reporter constructs in 293T cells and quantified nuclear localization following $\mathrm{H}_{2} \mathrm{O}_{2}$ exposure for $1 \mathrm{~h}$. Figure $3 \mathrm{~A}$ and Supplementary Figure S3A show that unlike WT FOXO3, C31S- and C150S-mutant FOXO3s fail to translocate to the nucleus, even during a highdose $\mathrm{H}_{2} \mathrm{O}_{2}$ treatment. These data indicate that FOXO3 C31 and $\mathrm{C} 150$ regulate $\mathrm{FOXO} 3$ nuclear translocation. A wellknown mechanism regulating FOXO3 nuclear localization is phosphorylation on T32 by AKT, which sequesters FOXO3 in the cytosol (6). We therefore examined the AKT phosphorylation status of $\mathrm{C} 31 \mathrm{~S}$ and $\mathrm{C} 150 \mathrm{~S}$ FOXO3 mutants. Figure 3B (Supplementary Slide S3B) shows that FOXO3 WT T32 phosphorylation levels were increasing following treatment with $\mathrm{H}_{2} \mathrm{O}_{2}$, which corresponded with binding of 14-3-3 to the PRDX1-FOXO3 complex (Supplementary Fig. S3B and Supplementary Slide S3B). Interestingly, both mutants showed increased basal levels of T32 phosphorylation compared to FOXO3 WT, with phosphorylation further increasing with additional $\mathrm{H}_{2} \mathrm{O}_{2}$ treatment. We also examined phosphorylation at S318, another AKT phosphorylation site known to enhance FOXO3 nuclear export (48), and found no change in phosphorylation levels between FOXO3 WT and the C31S and C150S single FOXO3 mutants (Supplementary Fig. S3C and Supplementary Slide S3C), suggesting the binding of PRDX1 to FOXO3 has a site-specific effect on FOXO3 phosphorylation. Given that FOXO3 C31S and C150S mutants have increased T32 phosphorylation and dysfunctional translocation in response to high doses of $\mathrm{H}_{2} \mathrm{O}_{2}$ (Fig. 3A, B), we questioned if PI3K inhibition is capable of promoting FOXO3 $\mathrm{C} 31 \mathrm{~S}$ and $\mathrm{C} 150 \mathrm{~S}$ mutant nuclear translocation. To do so, we applied experimental conditions that would decrease the activation of kinases such as STK4/

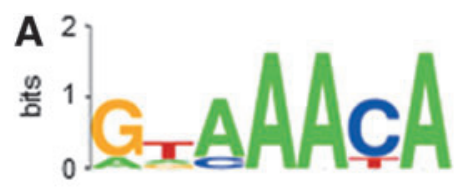

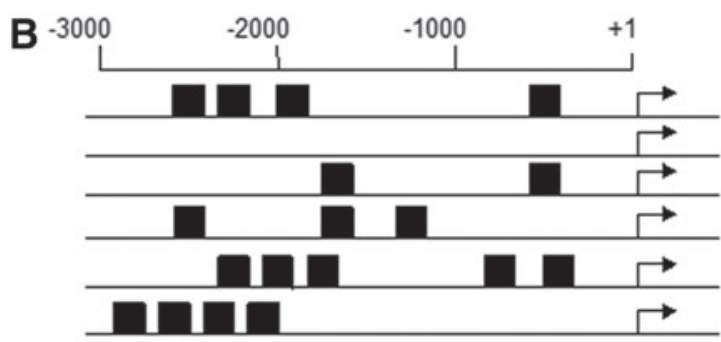

Homo sapiens MIRLETBHG Homo sapiens MIRLETTB Mus musculus Mirlet7b Rattusnorvegiaus Mirlet7b Danio rerio Mirlet7b Gallus gallus Mirlet7b

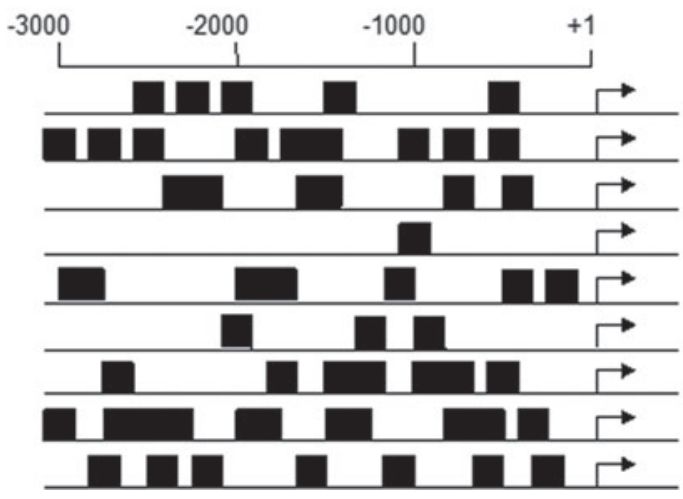

Homo sapiens MIR99AHG Homo sapiens MIRLETTC Mus musculus Mirlet7c-1 Mus musculus Mirlet7c-2 Rattus norvegicus Mirlet7c-1 Rattus norvegiaus Mirlet7c-2 Danio rerio Mirlet7a-1 Danio rerio Mirlet7a-2 Gallus gallus Mirlet7c
FIG. 4. FOXO3 consensus binding sequence found in let-7b and let-7c promoter region. (A) Putative $\mathrm{FOXO} 3$ binding sequence (10). (B) Putative FOXO binding motifs in forward and reverse are located in the $5^{\prime}$ UTR of let-7b and $-7 \mathrm{c}$ in several species. The consensus FOXO binding sequences in the WebLogo (black boxes) are indicated. Numbering is relative to the transcription start site obtained through the University of California Santa Cruz Genome Browser. UTR, untranslated region. 
A

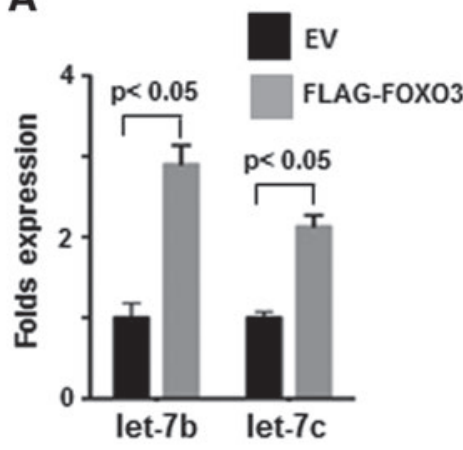

B

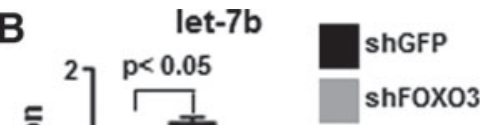

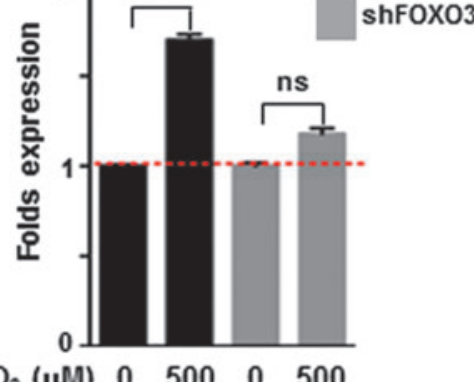
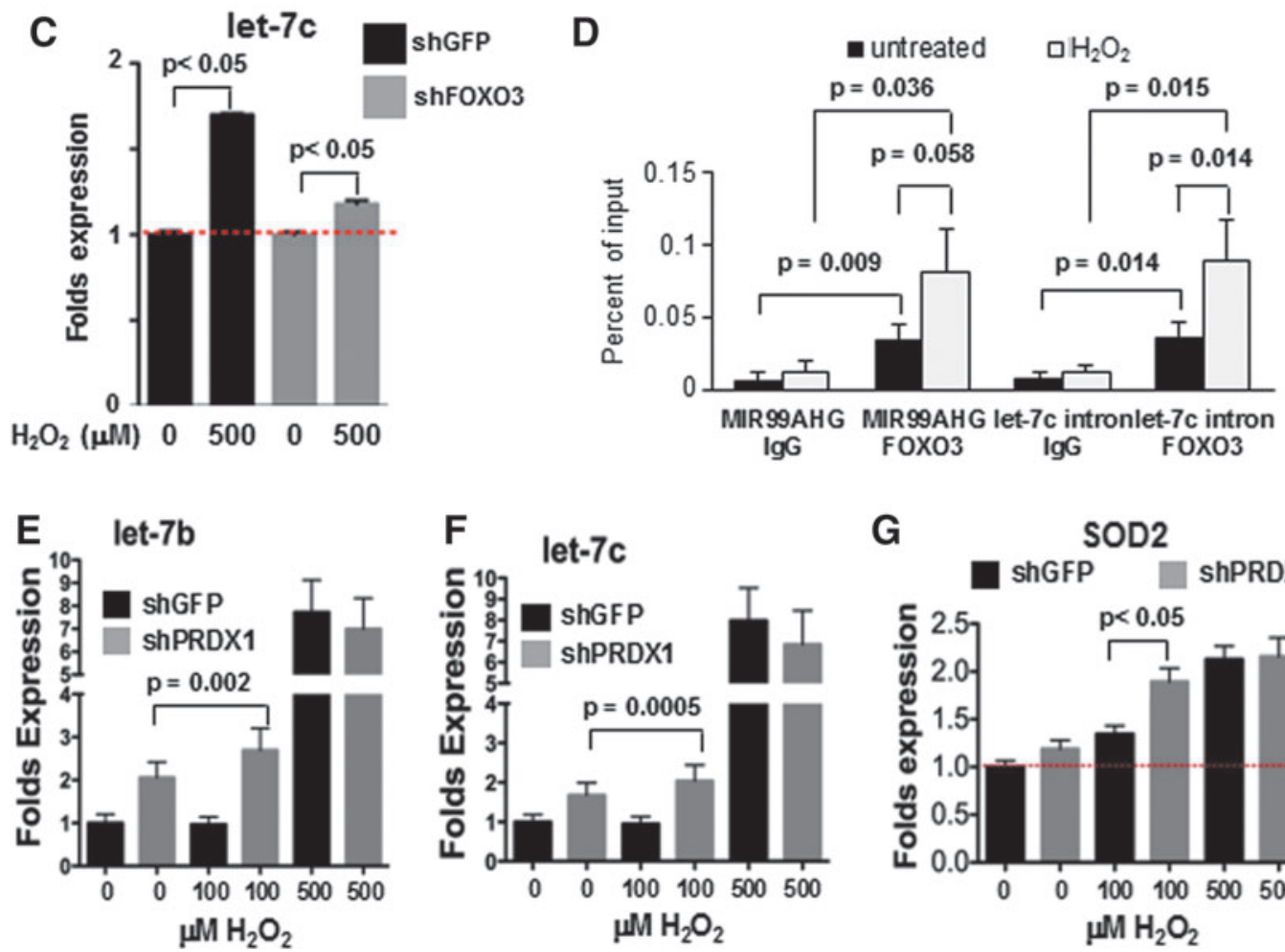

G

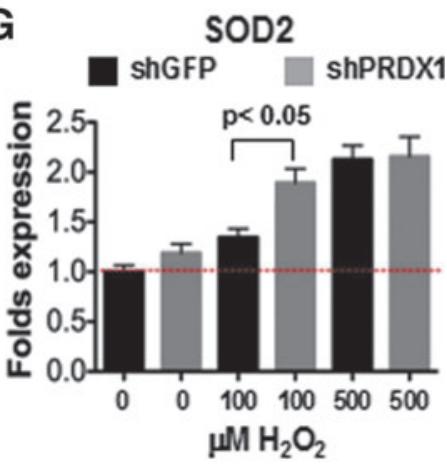

FIG. 5. FOXO3 regulates expression of let-7 miRNAs under $\mathbf{H}_{2} \mathbf{O}_{2}$. (A) Overexpression of FLAG-FOXO3 enhanced let-7b and $\mathrm{c}$ transcription in Hela cells $48 \mathrm{~h}$ after transfection. Cells were harvested, lysed, and analyzed for miRNA expression by TaqMan assays, using the delta $\mathrm{C}_{\mathrm{T}}$ method with mir-30c as the internal standard. (B, C) FOXO3-deficient HeLa cells were nonresponsive to $\mathrm{H}_{2} \mathrm{O}_{2}$ treatment. Thirty hours following transfection of shGFP or shFOXO3, cells were treated with or without $\mathrm{H}_{2} \mathrm{O}_{2}$ for $18 \mathrm{~h}$. Expression profiles of let- $7 \mathrm{~b}$ and let-7c were assessed by individual TaqMan assays with U18 as the internal standard $(N=3)$. (D) ChIP assays indicate transfected FLAG-FOXO3 binds to the MIR99AHG and intronic let-7c promoter regions and is enhanced following $100 \mu M \mathrm{H}_{2} \mathrm{O}_{2}$ treatment for $30 \mathrm{~min}$ in 293T cells. Quantification of immunoprecipitated DNA was performed in triplicate by quantitative PCR and evaluated by the delta $\mathrm{C}_{\mathrm{T}}$ method. Values of each immunoprecipitated sample are expressed as a percentage relative to their respective input (no antibody). (E-G) let$7 \mathrm{~b}$ and $\mathrm{c}$ transcription was increased in PRDX1-deficient cells. HeLa cells were transfected with either a shGFP or shPRDX1 construct for $56 \mathrm{~h}$, followed by treatment with or without $\mathrm{H}_{2} \mathrm{O}_{2}$ for $18 \mathrm{~h}$. HeLa cells were analyzed for gene expression by TaqMan expression assays using the delta $\mathrm{C}_{\mathrm{T}}$ method with $\mathrm{U} 18$ as the internal standard $(\mathbf{F}, \mathbf{G})$ or $\beta$-actin as the internal standard $(\mathbf{H})$.

MST1, JNK, and p38 $(23,31)$, known to induce FOXO3 nuclear localization by phosphorylating FOXO3. For example, MST1 phosphorylation on FOXO3 is known to overcome its AKT-induced cytoplasmic retention by decreasing 14-3-3 binding to FOXO3 (31). EGFP-FOXO3 localization was compared in 293T cells treated with $100 \mu M \mathrm{H}_{2} \mathrm{O}_{2}$ for 30 min. Under this treatment, 14-3-3 binding to FOXO3 was not decreased (Supplementary Fig. S3B). In addition, as FOXO3 nuclear localization is dependent on DNA concentration (Supplementary Fig. S3D), we assessed EGFP-FOXO3 localization of $50 \mathrm{ng}$ of EGFP-FOXO3 in a subconfluent population of cells to ensure AKT activity toward FOXO3 (26). We found that LY294002 (PI3K inhibitor) treatment significantly increased nuclear localization by $5.7 \%, 11.7 \%$, and $25 \%$ in FOXO3WT, FOXOC31S, and FOXOC150C, respectively, compared to untreated cells (Fig. 3C, D). These results 
A
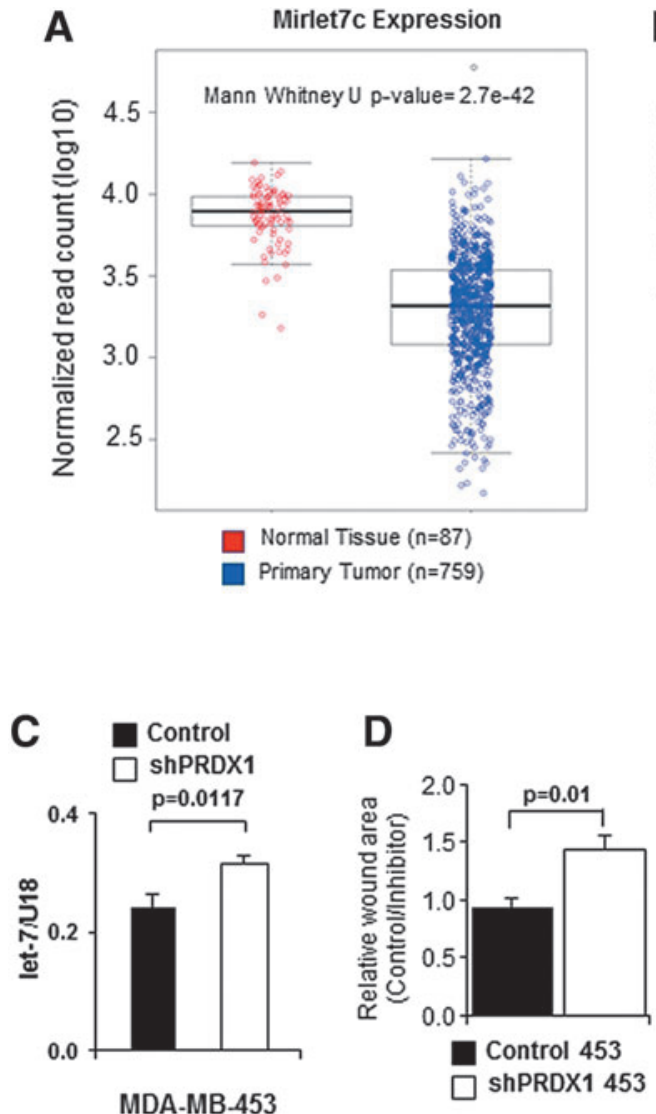
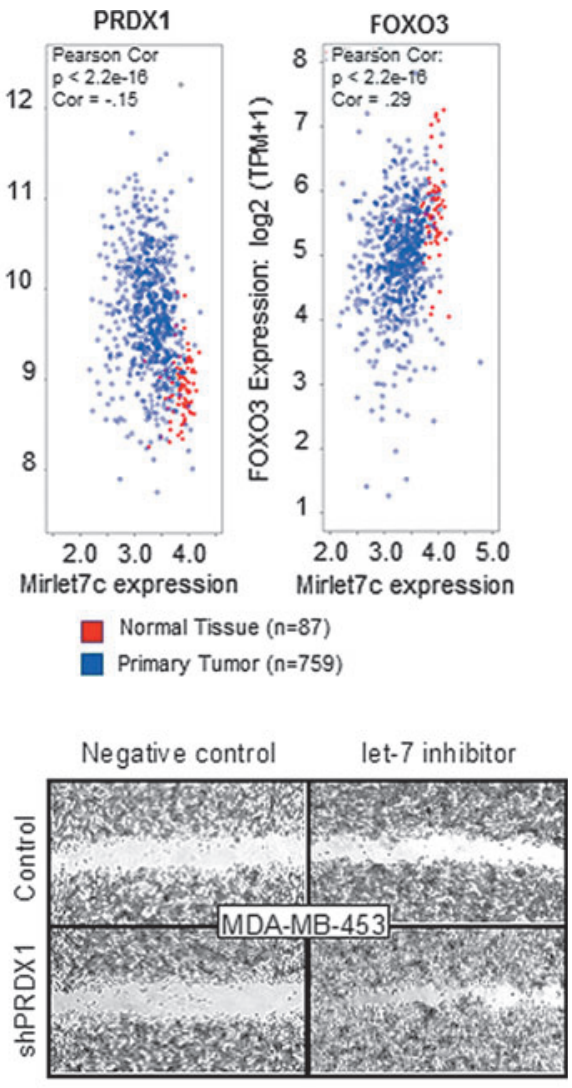
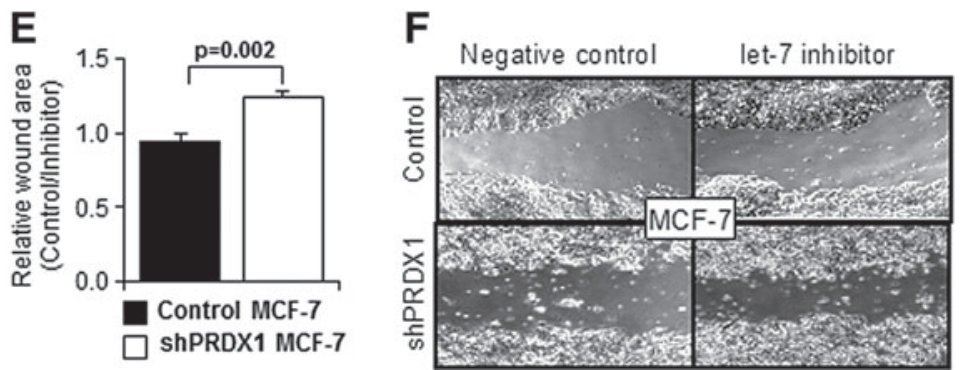

FIG. 6. Lack of PRDX1 enhances levels and function of let-7 miRNAs under $\mathbf{H}_{2} \mathbf{O}_{2}$. (A) Mirlet7 expression in normal and breast cancer tissue from TCGA. (B) Expression of FOXO3 and PRDX1 from TCGA breast cancer cases and normal tissue was compared to Mirlet7c expression. (C) EV or shPRDX1 MDA-MB-453 cells were harvested, lysed, and analyzed for miRNA expression by TaqMan assays using the delta $\mathrm{C}_{\mathrm{T}}$ method with U18 as the internal standard $\quad(N=3) . \quad(\mathbf{D}-\mathbf{E})$ Wound healing was increased following let-7 inhibition in PRDX1-deficient breast cancer cells. $1 \times 10^{6}$ shPRDX1 MDA-MB-453 or MCF-7 (white bar) cells or control (black bar) cells were transfected with a let-7 miRNA inhibitor in a 12-well plate and wound healing was assessed after $48 \mathrm{~h}$ (MDA-MB$453)$ or $24 \mathrm{~h}$ (MCF-7) in the presence of mitomycin $\mathrm{C}$ $(0.5 \mu \mathrm{g} / \mathrm{ml})$. Wound area of let-7 inhibitor-treated cells was normalized to control miRNA inhibitor-treated cells (mean + SE) $N=4$. Right side, representative photographs of wound healing assays in MDA-MB-453 or MCF-7 cells. TCGA, The Cancer Genome Atlas. suggest again that AKT-induced phosphorylation of FOXO3 sequesters FOXO3 cysteine mutants in the cytosol.

\section{Loss of PRDX1 enhances FOXO3-dependent $\mathrm{H}_{2} \mathrm{O}_{2}$-induced let-7 miRNA upregulation}

As prior studies have reported, increased let-7 family member expression is induced by ionizing radiation, genotoxic stress, and peroxide $(52,53)$. In Caeorhabditis elegans, let-7 family members have overlapping functions with FOXO proteins to regulate development, aging, glucose metabolism, stress responses, and act as tumor suppressors (5). We were interested to examine if let-7 miRNAs are regulated by FOXO3 under oxidative stress. Using the University of California Santa Cruz Genome Browser, we analyzed the $5^{\prime}$ untranslated region (UTR) of let-7b and let-7c in several species for putative FOXO3 binding sequences (YTXXACA) (10). As shown in Figure 4A and B, FOXO3 binding sites are preserved in the $5^{\prime}$ UTR of MIRLET7B and MIRLET7C.
To confirm let-7 miRNAs as a potential novel FOXO3 target, we established that $\mathrm{H}_{2} \mathrm{O}_{2}$ treatment of HeLa cells enhanced the expression of both let-7b and let-7c miRNAs (Supplementary Fig. S4A). To determine if FOXO3 is involved in $\mathrm{H}_{2} \mathrm{O}_{2}$-mediated enhanced expression of let-7b and let-7c in HeLa cells, we performed either an overexpression or a shRNA-mediated knockdown of FOXO3 before treatment with $\mathrm{H}_{2} \mathrm{O}_{2}$. When FOXO3 expression increased, levels of let-7b and let-7c were threefold and twofold higher, respectively (Fig. 5A and Supplementary Fig. S4B). As FOXO3 expression was significantly diminished, the ability of $\mathrm{H}_{2} \mathrm{O}_{2}$ to induce either let-7b or let-7c miRNA expression was lost (Fig. 5B, C, and Supplementary Fig. S4C). As a final confirmation of FOXO3s role in the $\mathrm{H}_{2} \mathrm{O}_{2}$-mediated enhancement of let-7 expression, a chromatin IP (ChIP) assay was performed showing that FOXO3 binds directly to both of the let-7c promoter regions, the distal host gene and the proximal intronic promoter, both considered functional in let7c transcription (44) (Fig. 5D and Supplementary Fig. S4D). FOXO3 promoter binding was further enhanced following 
$100 \mu M \mathrm{H}_{2} \mathrm{O}_{2}$ treatment compared to no treatment. These data suggested that FOXO3 very likely regulates the expression of MIRLET7B and MIRLET7C. Next, we examined if loss of PRDX1 magnifies let-7 miRNA transcription in the context of $\mathrm{H}_{2} \mathrm{O}_{2}$ addition. Figure 5E and $\mathrm{F}$ show when PRDX1 expression was more than $90 \%$ reduced (Supplementary Fig. S4E), let-7b and let-7c expression levels were augmented. This effect was further enhanced with $100 \mu M \mathrm{H}_{2} \mathrm{O}_{2}$ treatment. Moreover, SOD2, an established target of FOXO3, was also increased on $\mathrm{H}_{2} \mathrm{O}_{2}$ treatment in the context of PRDX1 knockdown (Fig. 5G). In conclusion, these data suggest that a PRDX1/FOXO3 signaling axis exists that directly regulates let-7c expression under $\mathrm{H}_{2} \mathrm{O}_{2}$-induced stress.

The PRDX1-FOXO3-let-7 axis regulates breast cancer cell migration

Finally, we sought functional confirmation of the PRDX1FOXO3-let-7 axis. As genetic alterations in cancer cells elevate the production of ROS, reviewed in Ref. (43) and let$7 \mathrm{~b}$ and let-7c suppress cancer development (5), including breast cancer $(13,59,65)$, we compared let-7c expression levels in normal and breast cancer cases (8). We found let-7c expression to be significantly lower in breast cancer tissues compared to normal breast tissue (Fig. 6A). FOXO3 showed a similar expression pattern to let-7c, while PRDX1 expression was increased in breast cancer compared to normal tissue (Supplementary Fig. S5A, B). Comparing changes to PRDX1 and FOXO3 expression in normal and breast cancerous tissues using Pearson correlation demonstrated a significant negative correlation for PRDX1 and FOXO3 in this data set downloaded from GEO Accession: GSE62944 (47) (Fig. 6B), suggesting functional significance of our findings. This was further substantiated analyzing breast cancer patient survival in data sets from the Kaplan-Meier Plotter (21) and the Gene Expression-based Outcome for Breast Cancer Online (GOBO) (18), which showed that a lower expression of FOXO3 and a higher expression of PRDX1 correlate with shortened patient survival (Supplementary Fig. S5C-F).

FOXO3 suppresses cancer development in different ways, including the inhibition of cell motility $(2,4,34,40,55,56)$. In contrast, while PRDX1 prevents cancer initiation $(37,38)$, its role in cancer is less understood. Interestingly, we have previously shown that PRDX1 deficiency in MCF-10A, MCF-7, and MDA-MB-231 cells increased p38 activation (61), which induces FOXO3 nuclear localization in MCF-7 cells $(12,23)$. We therefore hypothesized that inhibition of let-7b and let-7c would affect migration differently in breast cancer cells (MDA-MB-453 or MCF-7) with knockdown of PRDX1 (shPRDX1) (Supplementary Fig. S5G and Supplementary Slide S5G) compared to control vector treatment. Intriguingly, cells with reduced PRDX1 showed a $30 \%$ increase in let-7 expression (Fig. 6C) and a 50\% (MDA-MB453 ) and a $30 \%$ (MCF-7) increased wound closure, respectively, when transfected with single-stranded RNA oligonucleotide inhibitors that compete with let-7b and let-7c seed sequences (Fig. 6D, E). However, when compared with a negative control single-strand RNA oligonucleotide, we saw little to no wound closure between the control and shPRDX1 cells. Altogether, these data demonstrate that a PRDX1 regulated signaling axis exists in breast cancer and is required for
FOXO3 and let-7 miRNA upregulation to suppress breast cancer cell migration.

\section{Discussion}

$\mathrm{H}_{2} \mathrm{O}_{2}$ is an important second messenger in cell signaling, where it can directly induce oxidation of cysteine sulfhydryl groups in proteins, thereby impacting protein activity and facilitating rapid signal transfer comparable to other posttranslational modifications (49). Thus, oxidative equivalents can be passed on by $\mathrm{H}_{2} \mathrm{O}_{2}$-scavenging enzymes such as peroxidases (50). This reaction entails a transient disulfide exchange reaction between cysteine thiols, which requires close proximity of the peroxidase with a partnering protein (20). Peroxiredoxins have been suggested to form disulfide bridges with partnering proteins to pass oxidizing equivalents this way, thereby modulating protein activity of their binding partners $(28,57)$. Our data suggest a similar mechanism between PRDX1 and the transcription factor FOXO3. As the disulfide exchange reaction is transient, capture of stable complexes by co-IP is low as demonstrated by weak PRDX1 staining FLAG-FOXO3 pull down experiments despite the high abundance of PRDX1 in cell lysate (Fig. 1B, C).

FOXO family members have been implicated in ROS signaling involving cysteine thiols. For example, a recent study showed p300 to form disulfide reactions with FOXO4 that result in its acetylation and nuclear localization (14). However, more examples are needed to fully understand specific roles of FOXO proteins in redox response. We present for the first time, evidence of an $\mathrm{H}_{2} \mathrm{O}_{2}$-dependent regulation of FOXO3 activity directly through the oxidative stress-signaling sensor PRDX1. Our data suggest the formation of a disulfide bond between a PRDX1 dimer and FOXO3 monomer involving the PRDX1 peroxidatic and resolving cysteines C52 and C173, respectively, as well as $\mathrm{C} 71$. In FOXO3, the FOXO3 $\mathrm{C} 31$ is a shared cysteine among FOXO family members, while $\mathrm{C} 150$ is unique to FOXO3, suggesting a redox regulation that is specific for FOXO3 (Fig. 2). We further show the importance of PRDX1-FOXO3 binding by demonstrating increased FOXO3 cytoplasmic sequestration (Fig. 3A) due to increased AKT phosphorylation of FOXO3 mutants impaired in PRDX1 binding after $\mathrm{H}_{2} \mathrm{O}_{2}$ treatment (Fig. 3B-D). However, a further delineation of the FOXO-PRDX1 signaling pathway is warranted to determine the role that other family members may play, as a recent proteomic profiling report found that PRDX1, 2, and 5 are cysteine-dependent binding partners of FOXO3 and suggested that competition among PRDX family members may be present for FOXO3 binding (45).

We show that the PRDX1-FOXO3 complex formed in the presence of elevated $\mathrm{H}_{2} \mathrm{O}_{2}$ is a cysteine-dependent oligomer. A unique property to the PRDX1-FOXO3 axis is the utilization of $\mathrm{C} 150$ of FOXO3, which is exclusive to FOXO3, suggesting specificity of the PRDX1-FOXO3 interaction. Mutation of $\mathrm{C} 31$ or $\mathrm{C} 150$ inhibits FOXO3 complex formation with PRDX1 and renders these FOXO3 mutants unresponsive to oxidative insult, exhibiting cytoplasmic accumulation, which suggests PRDX1 binding of FOXO3 via disulfide bonds is critical for regulating FOXO3 in response to oxidative stress (Figs. 2 and 3). Luciferase reporter assays indicated FOXO3 becomes unresponsive to PRDX1induced control following treatment with high doses of $\mathrm{H}_{2} \mathrm{O}_{2}$ (Fig. 2G-I), suggesting over-oxidation of PRDX1 impairs 


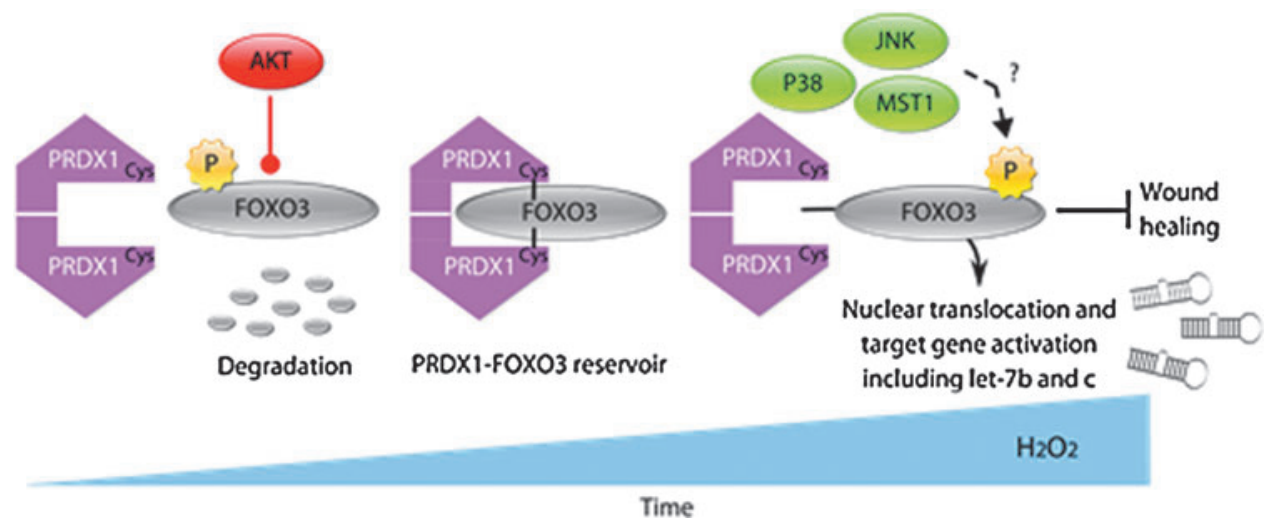

FIG. 7. Model: stepwise oxidation of PRDX1 regulates FOXO3 under oxidative stress. PRDX1 and FOXO3 interact in an oxidative stress-dependent way. This involves the catalytic/peroxidatic cysteine and C71 of PRDX1 and C31 and C150 of FOXO3. Our data strongly suggest disulfide bonding between PRDX1 and FOXO3 involving PRDX1 C52, C71, and $\mathrm{C} 173$ and FOXO3 $\mathrm{C} 31$ and $\mathrm{C} 150$ regulating the AKT-induced phosphorylation of T32 on FOXO3 and 14-3-3 binding and dissociation. Nuclear localization and 14-3-3 dissociation of FOXO3 may be promoted by monoubiquitination or phosphorylation by over-oxidized PRDX1 activating MST1 or oxidative stress activation of JNK or p38. This results in expression in let-7b and let-7c and inhibition of migration.

FOXO3 binding and may also allow FOXO3 posttranslational modifications to induce nuclear translocation (Fig. 1E). FOXO3 C31 or C150 mutants (Fig. 3C, D) were unresponsive to $\mathrm{PRDX} 1$ regulation, but surprisingly correlated with cytosolic sequestration under $\mathrm{H}_{2} \mathrm{O}_{2}$-induced stress (Fig. 3A) compared to FOXO3WT. To determine why FOXO3 C31S and C150S mutants could not bind PRDX1, but were sequestered from the nucleus (Fig. 3A), the phosphorylation status of FOXO3 T32 and S318, which represses FOXO3 through AKT and SGK signaling (7), was probed. Interestingly, wild-type FOXO3 showed an $\mathrm{H}_{2} \mathrm{O}_{2}$-dependent increase in T32 phosphorylation, however, FOXO3 cysteine mutants displayed much higher phosphorylation. FOXO3C $31 \mathrm{~S}$ showed an overall higher phosphorylation of T32, while FOXO3C150 T32 phosphorylation was higher than FOXO3WT but not as responsive to $\mathrm{H}_{2} \mathrm{O}_{2}$ stimulation (Fig. 3B). Analysis of S318 phosphorylation, however, showed no difference between wild-type FOXO3 and the FOXO3 cysteine mutants (Supplementary Fig. S3C), suggesting that PRDX1 binding to FOXO3 is site specific and calibrates T32 phosphorylation, but not S318.

FOXO3 nuclear localization is regulated by AKT and SGK phosphorylation inducing 14-3-3 binding and cytoplasmic sequestration or kinases that induce nuclear localization. Candidate kinases include MST1, JNK, or p38 (19, 23) (Fig. 7), where MST1 can induce nuclear localization of an AKT phosphorylated FOXO3 protein (31). Interestingly, all three kinases are subject to PRDX1 binding and subsequent regulation, indicating another layer of control in the PRDX1/FOXO3/ let-7c axis that requires future analysis. We suspect that under high oxidative stress, MST1, an essential activator of FOXO and repressor of $\mathrm{AKT}(11,31)$, is activated by PRDX1 decamers (formed by 10 over-oxidized PRDX1 proteins) (35) under higher oxidative stress causing phosphorylation of FOXO3 on S207. This suggests that FOXO3 nuclear localization under $\mathrm{H}_{2} \mathrm{O}_{2}$-induced stress may increase in the presence of decameric (over-oxidized) PRDX1. This is in alignment with our findings that PRDX1 binding to FOXO3 does not include over-oxidized PRDX1 protein (Supplementary Fig. S1A) and is dynamic as it decreases after $30 \mathrm{~min}$ in $\mathrm{H}_{2} \mathrm{O}_{2}$-treated cells (Fig. 1C). On the contrary, kinase activity of JNK and p38 is inhibited by PRDX1, perhaps accounting for the increased localization of FOXO3 in the nucleus in PRDX1-deficient cells compared to PRDX1proficient cells (Fig. 1E and Supplementary Fig. S1C). This suggests different roles for PRDX1 on FOXO3 signaling and needs further exploration in future studies. Further exploring our findings that PRDX1 binding to FOXO3 calibrates FOXO3 nuclear translocation through modulating AKT phosphorylation, we demonstrate that $\mathrm{PI} 3 \mathrm{~K}$ inhibition rescued translocation of C31S and C150S mutant FOXO3 to FOXOWT levels following $\mathrm{H}_{2} \mathrm{O}_{2}$ exposure (Fig. 3C, D).

Collectively, these data suggest an oxidative stressdependent mechanism of FOXO3 cytoplasmic loading, a protection and release that are directed through PRDX1 by binding to FOXO3 and coordinating its posttranslational modifications (Fig. 7). Accordingly, PRDX1-dependent protection of FOXO3 from repressive phosphorylation and degradation pathways would enable a FOXO3 reservoir not reliant on de novo synthesis of FOXO3 or T32 dephosphorylation. The PRDX1-FOXO3 axis therefore is more than simply an inhibitory pathway, but rather, a redox-dependent signaling modulator enabling controlled bursts of FOXO3 nuclear translocation and gene expression. Based on our data shown here, we propose that PRDX1 builds a stepwise and redox-dependent FOXO3 cytoplasmic reservoir that is readily available once high $\mathrm{H}_{2} \mathrm{O}_{2}$ levels stimulate FOXO3 nuclear function (Supplementary Fig. S6).

miRNAs are direct targets of transcription factors that are known as important tumor suppressors or oncogenic proteins. Yet, remarkably little is understood of miRNAs that are responsive to FOXOs. Consensus FOXO DNA binding motifs are present in the $5^{\prime}$ UTR of let-7b and let-7c in several species (Fig. 4). Interestingly, let-7b and let-7c-2 in Mus musculus and Rattus norvegicus are located in tandem and separated by 621 and 319 nucleotides, respectively. Our results establish for the first time that let-7b and let-7c are upregulated by FOXO3 (Fig. 5) directly to both of let-7c promoter regions (the distal host gene and the proximal intronic promoter) considered functional in let-7c transcription (44) (Fig. 5D and Supplementary Fig. S4D). In addition, 
FOXO3 promoter binding is enhanced following $100 \mu M$ $\mathrm{H}_{2} \mathrm{O}_{2}$ treatment compared to no treatment (Fig. 5D). These data define a new facet of FOXO3-mediated responses to oxidative stress, as our findings are consistent with prior reports that show let- 7 members are upregulated by ionizing radiation, genotoxic stress, and peroxide $(52,53)$. Intriguingly, we identified a novel FOXO3 target with direct tumor suppressive activity, as let-7 miRNAs bind to $3^{\prime}$ UTRs of target oncogenes and cell cycle regulators and that reduced let-7 expression has been shown to correlate with the development of cancers (64).

Systemic deletion of FOXOs results in cancer in murine models in vivo, underscoring their role as bona fide tumor suppressors (42). In addition, inactivating genetic mutations and reduced expression of FOXOs occur in human cancers (3, 24 ), and suppression of FOXO function is critical in promoting evasion of apoptosis and is a significant occurrence in several hematological malignancies, including Bcr-Abl+ leukemia $(17,27)$. Notably, a more specific role has been identified for FOXO3 as an inhibitor of cancer cell motility $(40,56)$ and wound healing (51), suggesting that FOXO3 may regulate cell motility.

Similar to FOXOs, PRDX1 protects from tumor initiation (38), however, in contrast to FOXO3, several reports indicate poor prognosis for cancers with high expression of PRDX1 $(29,58,67)$. This is in line with The Cancer Genome Atlas and survival analyses showing PRDX1 expression elevated in breast cancer patients with decreased survival (Fig. 6B and Supplementary Fig. S5C-F). Importantly, these data support our findings that a PRDX1-FOXO3-let-7 axis exists in tumorigenesis. Furthermore, PRDX1-deficient MDA-MB-453 cells showed increased levels of let-7c (Fig. 6C) and let-7 inhibition increased cell motility of MDA-MB-453 and MCF-7 breast cancer cells, both of which show low motility (1), with decreased PRDX1 expression (Fig. 6D, E). This finding is consistent with earlier studies showing that let-7 miRNAs inhibit motility of breast cancer cells by regulating genes in the actin cytoskeleton pathway (25). Given the findings of these studies and those presented here, it would be interesting in future studies to determine let-7 miRNA targets that are controlled by PRDX1 and FOXO3 in cancer development.

The free radical theory of aging posits that accumulated damage from oxidative events shortens life span. The fundamental importance of PRDX1 in protecting from the deleterious effects of oxidative stress is best illustrated by the multiple cancers and shortened life span in Prdxl-deficient mice (38). Moreover, hyperactivation of FOXO proteins has been implicated in extending life span (63). Our data suggest that $\mathrm{FOXO} 3$ fine tunes cellular homeostasis in response to cellular redox through integration with PRDX1. Because ROS are fundamental in driving the aging process and in the development of cancers, this new mechanism we describe here adds to our understanding of how the evolutionarily conserved FOXO C31 in conjunction with C150 may be instrumental in the regulation of aging and tumor suppression.

\section{Materials and Methods}

\section{Cell culture}

293T (HEK 293T) and HeLa cells were obtained from ATCC. These cells were grown in DMEM (Mediatech) supplied with $10 \%$ heat-inactivated FBS (HyClone), $100 \mathrm{U} / \mathrm{ml}$ penicillin, $100 \mathrm{mg} / \mathrm{ml}$ streptomycin (Mediatech), and $2 \mathrm{mM}$ L-glutamine (Mediatech) (complete DMEM) in a $37^{\circ} \mathrm{C}$ incubator supplied with $5 \% \mathrm{CO}_{2} . P r d x 1^{+/+}$and $\operatorname{Prd} x 1^{-/-} \mathrm{MEFs}$ were generated as described in Ref. (9) from Prdxl knockout and parental mice (38) and grown in the same conditions as the 293T. Except when otherwise stated, chemicals used were obtained from Sigma.

\section{Plasmids}

pcDNA3-FLAG, pcDNA3-FLAG-HA, pcDNA3-FLAGFOXO3, and pcDNA3-FLAG-HA-FOXO3 have previously been described (54). Site-directed mutagenesis of FOXO3 plasmids was performed using the Stratagene QuikChange II XL kit (Agilent Technologies) following the manufacturer's guidelines. The oligonucleotides used were designed using the online QuikChange Primer design application (Agilent Technologies) and were synthesized from Integrated DNA Technologies. The pcDNA3-FLAG-HA-FOXO3 plasmid was used as a template to generate all five single C-to-S mutants. Each clone obtained was sequenced with four different sequencing primers to span, with overlaps, the entire coding sequence. To generate the double, quadruple, and quintuple C-to-S mutants, newly synthesized single Cys-toSer mutants were used as templates for successive mutagenesis rounds with full-length sequencing after each round. To generate the Cys-to-Ser mutants of pcDNA3-FLAGFOXO3, the inserts of the several C-to-S mutants of pcDNA3-FLAG-HA-FOXO3 were excised with a BamH1Xho1 (New England Biolabs) restriction enzyme digestion and cloned into the pcDNA3-FLAG-FOXO3 plasmid, also digested with BamH1 and Xho1 to remove the unmutated FOXO3 insert. shRNA for FOXO3 (NM_001455.X-2766s1c1 clone) was purchased from Sigma. shPRDX1 expression constructs were used as previously described (61).

\section{$\mathrm{FOXO} 3-\mathrm{H}_{2} \mathrm{O}_{2}$ dosage}

HEK 293 T cells $\left(5 \times 10^{5}\right)$ were transiently transfected with $2 \mu \mathrm{g}$ pcDNA3-FLAG-HA (EV) or pcDNA3-FLAG-FOXO3 plasmids, using the FuGENE 6 system for $48 \mathrm{~h}$. Cells were serum starved for $30 \mathrm{~min}$ and then treated with 0, 25, 100, 250, or $500 \mu M \mathrm{H}_{2} \mathrm{O}_{2}$ for $30 \mathrm{~min}$. Samples were lysed using a tris lysis buffer ( $50 \mathrm{~m} M$ Tris; $2 \%$ Triton X-100; $0.5 \mathrm{~m} M$ EDTA; $0.5 \mathrm{~m} M$ EGTA; $150 \mathrm{~m} M \mathrm{NaCl} ; 10 \%$ glycerol; $50 \mathrm{~m} M \mathrm{NaF}$; $1 \mathrm{mM} \mathrm{NaVO}$; $40 \mathrm{~m} M \beta$-glycerophosphate), supplemented with $30 \mu \mathrm{g} / \mathrm{ml}$ catalase from bovine liver (Sigma), and proteinase inhibitors. Protein concentrations were quantified using the Pierce BCA Protein Assay kit, according to the manufacturer's instructions (Thermo). One milligram of cell lysate was incubated with $20 \mu \mathrm{l}$ of acid-treated Anti-FLAG M2 Affinity Gel (Sigma) and $400 \mu \mathrm{l}$ lysis buffer, at $25^{\circ} \mathrm{C}$ for $3 \mathrm{~h}$, with rotation. Precipitated samples were collected and washed four times with lysis buffer and once with $1 \times$ TBS. Beads were boiled in Laemmli sample buffer (BioRad) in the presence or absence of $\beta$-mercaptoethanol (Sigma) for $10 \mathrm{~min}$. Twenty micrograms of whole cell lysate input was prepared in Laemmli sample buffer as above for $5 \mathrm{~min}$.

\section{FOXO3 C-to-S mutant transfection}

HEK 293 T cells $\left(5 \times 10^{5}\right)$ were transiently transfected with $2 \mu \mathrm{g} \mathrm{EV}$, pcDNA3-FLAG-FOXO3, or pcDNA-FLAG-HA- 
FOXO3 constructs containing various C-to-S mutations, using the FuGENE 6 system for $48 \mathrm{~h}$. Cells were serum starved for $30 \mathrm{~min}$ and then treated with 0 or $25 \mu M \mathrm{H}_{2} \mathrm{O}_{2}$. Samples were lysed using the tris lysis buffer detailed above, supplemented with $30 \mu \mathrm{g} / \mathrm{ml}$ catalase from bovine liver (Sig$\mathrm{ma}$ ), and proteinase inhibitors. Protein concentrations were quantified using the BCA protein assay (Thermo). IP of $1000 \mu \mathrm{g}$ (or $1500 \mu \mathrm{g}$ for nuclear localization) of cell lysate was processed as detailed above.

\section{PRDX1 C-to-S mutant transfection}

HEK 293 T cells $\left(5 \times 10^{5}\right)$ were cotransfected with pcDNAFLAG-FOXO3 and pcDNA3-HA-PRDX1 or pcDNA3-HAPRDX1 constructs containing various $\mathrm{C}$-to-S mutations using the FuGENE 6 system for $48 \mathrm{~h}$. Cells were serum starved for $30 \mathrm{~min}$ and then treated with 0 or $25 \mu M \mathrm{H}_{2} \mathrm{O}_{2}$. IP samples were prepared as above with $1.5 \mathrm{mg}$ of cell lysate for relative protein quantification.

\section{FOXO3-PRDX1 interaction in MEFs}

Confluent $\operatorname{Prdx} \mathrm{I}^{+/+}$and $\operatorname{Prdxl^{-/}}$ MEFs were serum starved for $30 \mathrm{~min}$ and then treated with 0,25 , or $250 \mu M \mathrm{H}_{2} \mathrm{O}_{2}$ for $30 \mathrm{~min}$. Cells were lysed in the aforementioned tris lysis buffer and $80 \mu \mathrm{g}$ of cell lysate was used for relative protein quantification.

\section{Western blotting}

Prepared IP samples and corresponding whole cell lysates were fractionated by SDS-PAGE and transferred to a nitrocellulose membrane according to the manufacturer (BioRad). Membranes were blocked with 5\% BSA in TBS for $30 \mathrm{~min}$ and incubated with antibodies against FOXO3 (1:1000; Abcam), P-FOXO3 T32 (1:1000; Cell Signaling), PRDX1 (1:4000; Abcam), PRDX-SO3 (1:500; Abcam), 143-3 (1:1000; Cell Signaling), or actin (1:1000; Oncogene) overnight at $4{ }^{\circ} \mathrm{C}$. Membranes were washed four times for $5 \mathrm{~min}$ in TBST $(0.05 \%$ Tween-20) and visualized by IR or chemiluminescent detection. For IR processing, membranes were incubated with a 1:15,000 dilution of anti-goat, anti-rabbit, or anti-mouse IRDye (LI-COR) for $30 \mathrm{~min}$ at $25^{\circ} \mathrm{C}$. Blots were washed with TBST three times and with TBS once, and imaged on an Odyssey (LI-COR) imager. Membranes processed by chemiluminescence were incubated in a 1:10,000 dilution of HRP-conjugated anti-mouse or anti-rabbit antibodies for $1 \mathrm{~h}$ at $25^{\circ} \mathrm{C}$. Blots were washed four times with TBST for $5 \mathrm{~min}$ and exposed to ECL for $1 \mathrm{~min}$.

\section{FOXO3 nuclear localization in $293 \mathrm{~T}$ cells}

Nuclear localization of $5.0 \times 10^{4} 293 \mathrm{~T}$ cells transiently transfected with FuGENE 6 for $24 \mathrm{~h}$ with $50 \mathrm{ng}$ EGFPFOXO3 or FOXO3-EGFP C31S or C150S mutants, transferred to complete media for $24 \mathrm{~h}$, serum starved for $1 \mathrm{~h}$, then treated with $100 \mu M \mathrm{H}_{2} \mathrm{O}_{2}$ or vehicle and $20 \mu M \mathrm{LY} 294002$ or vehicle for $30 \mathrm{~min}$, fixed with $2 \%$ paraformaldehyde for $15 \mathrm{~min}$, and quantified by blinded scoring of triplicate images from three separate experiments using a IX83 microscope (Olympus).

\section{FOXO luciferase assay}

FOXO signaling activity was quantified in mouse embryonic fibroblasts or HEK 293T cells utilizing the dualluciferase Cignal FOXO Luciferase Reporter assay (Qiagen). $2.5 \times 10^{5}$ MEFs were transiently cotransfected with $350 \mathrm{ng}$ Cignal reporter plasmids, $0.5 \mu \mathrm{g}$ of PRDX1 and FOXO3 or FOXO3 cysteine mutant plasmids, and compared to FOXO3 plus vector control samples. Transfections were performed with FuGENE 6 for $24 \mathrm{~h}$. Luciferase activity was normalized to the internal Renilla control. The effect of oxidative stress on FOXO3 activity was quantified in $293 \mathrm{~T}$ cells by transfection with $350 \mathrm{ng}$ Cignal reporter plasmid, $50 \mathrm{ng}$ FOXO3, or the FOXO cysteine mutants. Five hundred nanograms of PRDX1 was transfected into the cells $8 \mathrm{~h}$ later and incubated for an additional $14 \mathrm{~h}$. Luciferase activity was measured $1.5 \mathrm{~h}$ following $30 \mathrm{~min}$ of $0-250 \mu M \mathrm{H}_{2} \mathrm{O}_{2}$ treatment. Dualluciferase activity was measured in $1 \times$ passive lysis buffer using the manufacturer's protocol (Promega).

\section{Endogenous transcript quantification in $293 \mathrm{~T}$ cells}

$293 \mathrm{~T}$ cells $\left(2.5 \times 10^{5}\right)$ infected with pLKO.1 control or shPRDX1 plasmids were serum starved for $1 \mathrm{~h}$ and then treated with 0 or $250 \mu M \mathrm{H}_{2} \mathrm{O}_{2}$ for $16 \mathrm{~h}$. RNA was isolated utilizing the GeneJET RNA Purification Kit (Thermo Scientific) and converted to cDNA with the qScript cDNA synthesis kit (Quanta Biosciences). SESN3, P27, BIM, SOD2, CAT, and P21 transcripts were quantified by SYBR green real-time PCR (BioRad) relative to YWHAZ control using custom primers (Supplementary Table S1) and accounting for PCR efficiency.

\section{Quantitative real-time- $q P C R$}

Cell lysates were generated with the Cells-to-CT kit (Life Technologies). RT enzymes, individual TaqMan assays, and all PCR enzymes, dyes, and buffers were purchased from Life Technologies and used according to the manufacturer's suggestions. All qPCRs were run on an ABI 7900HT instrument.

\section{Cell viability assay}

HEK 293 T cells $\left(5 \times 10^{5}\right)$ were transiently transfected with $2 \mu \mathrm{g}$ pcDNA3-FLAG-FOXO3 plasmids, using the FuGENE 6 system for $24 \mathrm{~h}$. Cells were then trypsinized and then $2 \times 10^{4}$ cells were plated into the wells of a 96-well assay plate. The next day, the cells were treated with 0,250 , or $500 \mu M \mathrm{H}_{2} \mathrm{O}_{2}$ for $3 \mathrm{~h}$. Viability, cytotoxicity, and apoptosis were then measured using the ApoTox-Glo Triplex Assay (Promega), following the manufacturer's protocol.

\section{Wound healing assay}

One million MDA-MB-453 cells were infected with a pLKO. 1 shPRDX1 or control construct and then transfected in a 12-well plate with $25 \mathrm{n} M$ let-7 miRIDIAN microRNA hairpin inhibitor (GE Dharmacon) or miRIDIAN microRNA hairpin inhibitor negative control \#1 (GE Dharmacon) and $25 \mathrm{n} M$ siGLO Green Transfection Indicator (GE Dharmacon) utilizing $5 \mu \mathrm{l}$ DharmaFECT 2 transfection reagent (GE Dharmacon) per well. Confluent cultures were scratched with a $10 \mu \mathrm{l}$ pipette tip in the presence of mitomycin $\mathrm{C}$ and 
photographed after $48 \mathrm{~h}$ to measure wound healing. Wound area was quantified with the ImageJ plugin MRI Wound Healing Tool (Volker Bäcker). let-7b expression was used as an indicator of let-7 inhibition. The relative wound area was compared in PRDX1-deficient cells and control cells treated with the let-7 miRIDIAN inhibitor normalized to control microRNA hairpin inhibitor. Average values were compared from four separate experiments + standard error of the mean.

\section{ChIP Assay}

$293 \mathrm{~T}$ cells were seeded $\left(4 \times 10^{6}\right.$ cells/dish $\left.150 \mathrm{~mm}\right)$ and $24 \mathrm{~h}$ later transfected with EGFP-FOXO3 plasmid $(14 \mu \mathrm{g} /$ dish) by the calcium phosphate method. Forty-eight hours after transfection, complete medium was replaced with serum-free medium for $30 \mathrm{~min}$, followed by $\mathrm{H}_{2} \mathrm{O}_{2}(100 \mu M)$ treatment for $30 \mathrm{~min}$. Cells were crosslinked with $1 \%$ formaldehyde for $10 \mathrm{~min}$ at $25^{\circ} \mathrm{C}$ and then the reaction was stopped by addition of glycine to a final concentration of $0.125 M$. Crosslinked chromatin was immunoprecipitated with $1 \mu \mathrm{g}$ of FOXO3 antibody (ab12162; Abcam) as previously described (44). The genomic regions in the host gene and intronic promoter, close to FOXO3 binding sites, were amplified with primers designed by the Primer-Blast NCBI software (www.ncbi.nlm.nih.gov/tools/primer-blast). The following primer sequences were used: MIR99HG oligo\#1 FW: 5'-CTATGCGCCACTCTGTGCAA-3'; MIR99HG oligo\#1 RV: 5'-CTAATTACCGCGCACAAGCTG-3'; let-7c intronic prom oligo \#2 FW: 5'-GGCATAAACCCGTAGA TCCG-3'; let-7c intronic prom oligo \#2 RV: 5'-GAG CTTGTGCGGTCCACTT-3. Quantification of cDNA was performed in triplicate on an Applied Biosystems 7500 RealTime PCR System SDS v1,2, using the SYBR green dye detection method. ChIP assay results were evaluated by the double delta $\mathrm{C}_{\mathrm{T}}$ method.

\section{Acknowledgments}

This work was supported by NIH CA131350 and BBA UPITT (CAN), P30CA047904 (UPCI), the Cotswold Foundation postdoctoral fellowship (J.J.S.), and NIH CA131664 (R.K.-F.). We thank Robin Zaboulian for technical help.

\section{Author Disclosure Statement}

No competing financial interests exist.

\section{References}

1. Bailey CK, Mittal MK, Misra S, and Chaudhuri G. High motility of triple-negative breast cancer cells is due to repression of plakoglobin gene by metastasis modulator protein SLUG. J Biol Chem 287: 19472-19486, 2012.

2. Belguise K, Guo S, and Sonenshein GE. Activation of FOXO3a by the green tea polyphenol epigallocatechin-3gallate induces estrogen receptor alpha expression reversing invasive phenotype of breast cancer cells. Cancer Res 67: 5763-5770, 2007.

3. Blake DC, Jr, Mikse OR, Freeman WM, and Herzog CR. FOXO3a elicits a pro-apoptotic transcription program and cellular response to human lung carcinogen nicotinederived nitrosaminoketone (NNK). Lung Cancer 67: 37-47.
4. Borniquel S, Garcia-Quintans N, Valle I, Olmos Y, Wild B, Martinez-Granero F, Soria E, Lamas S, and Monsalve M. Inactivation of Foxo3a and subsequent downregulation of PGC-1 alpha mediate nitric oxide-induced endothelial cell migration. Mol Cell Biol 30: 4035-4044, 2010.

5. Boyerinas B, Park SM, Hau A, Murmann AE, and Peter ME. The role of let-7 in cell differentiation and cancer. Endocr Relat Cancer 17: F19-F36, 2010.

6. Brunet A, Bonni A, Zigmond MJ, Lin MZ, Juo P, Hu LS, Anderson MJ, Arden KC, Blenis J, and Greenberg ME. Akt promotes cell survival by phosphorylating and inhibiting a Forkhead transcription factor. Cell 96: 857-868, 1999.

7. Calnan DR and Brunet A. The FoxO code. Oncogene 27: 2276-2288, 2008.

8. Cancer Genome Atlas N. Comprehensive molecular portraits of human breast tumours. Nature 490: 61-70, 2012.

9. Cao J, Schulte J, Knight A, Leslie NR, Zagozdzon A, Bronson R, Manevich Y, Beeson C, and Neumann CA. $\operatorname{Prdx} 1$ inhibits tumorigenesis via regulating PTEN/AKT activity. EMBO J 28: 1505-1517, 2009.

10. Chen X, Ji Z, Webber A, and Sharrocks AD. Genomewide binding studies reveal DNA binding specificity mechanisms and functional interplay amongst Forkhead transcription factors. Nucleic Acids Res 44: 1566-1578, 2016.

11. Cinar B, Fang PK, Lutchman M, Di Vizio D, Adam RM, Pavlova N, Rubin MA, Yelick PC, and Freeman MR. The pro-apoptotic kinase Mst1 and its caspase cleavage products are direct inhibitors of Akt1. EMBO J 26: 4523-4534, 2007.

12. Clavel S, Siffroi-Fernandez S, Coldefy AS, Boulukos K, Pisani DF, and Derijard B. Regulation of the intracellular localization of Foxo3a by stress-activated protein kinase signaling pathways in skeletal muscle cells. Mol Cell Biol 30: 470-480, 2010.

13. D'Ippolito E and Iorio MV. MicroRNAs and triple negative breast cancer. Int J Mol Sci 14: 22202-22220, 2013.

14. Dansen TB, Smits LM, van Triest MH, de Keizer PL, van Leenen D, Koerkamp MG, Szypowska A, Meppelink A, Brenkman AB, Yodoi J, Holstege FC, and Burgering BM. Redox-sensitive cysteines bridge p300/CBP-mediated acetylation and FoxO4 activity. Nat Chem Biol 5: 664-672, 2009.

15. Davies MJ. Protein oxidation and peroxidation. Biochem $J$ 473: 805-825, 2016.

16. de Keizer PL, Burgering BM, and Dansen TB. Forkhead box $\mathrm{O}$ as a sensor, mediator, and regulator of redox signaling. Antioxid Redox Signal 14: 1093-1106, 2011.

17. Eijkelenboom A and Burgering BM. FOXOs: signalling integrators for homeostasis maintenance. Nat Rev Mol Cell Biol 14: 83-97, 2013.

18. Fredlund E, Staaf J, Rantala JK, Kallioniemi O, Borg A, and Ringner M. The gene expression landscape of breast cancer is shaped by tumor protein p53 status and epithelialmesenchymal transition. Breast Cancer Res 14: R113, 2012.

19. Fu Z and Tindall DJ. FOXOs, cancer and regulation of apoptosis. Oncogene 27: 2312-2319, 2008.

20. Gutscher M, Sobotta MC, Wabnitz GH, Ballikaya S, Meyer AJ, Samstag Y, and Dick TP. Proximity-based protein thiol oxidation by $\mathrm{H} 2 \mathrm{O} 2$-scavenging peroxidases. J Biol Chem 284: 31532-31540, 2009.

21. Gyorffy B, Lanczky A, Eklund AC, Denkert C, Budczies J, Li Q, and Szallasi Z. An online survival analysis tool to rapidly assess the effect of 22,277 genes on breast cancer 
prognosis using microarray data of 1,809 patients. Breast Cancer Res Treat 123: 725-731, 2010.

22. Hall A, Karplus PA, and Poole LB. Typical 2-Cys peroxiredoxins-structures, mechanisms and functions. Febs J 276: 2469-2477, 2009.

23. Ho KK, McGuire VA, Koo CY, Muir KW, de Olano N, Maifoshie E, Kelly DJ, McGovern UB, Monteiro LJ, Gomes AR, Nebreda AR, Campbell DG, Arthur JS, and Lam EW. Phosphorylation of FOXO3a on Ser-7 by p38 promotes its nuclear localization in response to doxorubicin. J Biol Chem 287: 1545-1555, 2012.

24. Hu MC, Lee DF, Xia W, Golfman LS, Ou-Yang F, Yang JY, Zou Y, Bao S, Hanada N, Saso H, Kobayashi R, and Hung MC. IkappaB kinase promotes tumorigenesis through inhibition of forkhead FOXO3a. Cell 117: 225237, 2004.

25. Hu X, Guo J, Zheng L, Li C, Zheng TM, Tanyi JL, Liang S, Benedetto C, Mitidieri M, Katsaros D, Zhao X, Zhang Y, Huang Q, and Zhang L. The heterochronic microRNA let-7 inhibits cell motility by regulating the genes in the actin cytoskeleton pathway in breast cancer. Mol Cancer Res 11: 240-250, 2013.

26. Imai $Y$, Takahashi A, Hanyu A, Hori S, Sato S, Naka K, Hirao A, Ohtani N, and Hara E. Crosstalk between the Rb pathway and AKT signaling forms a quiescence-senescence switch. Cell Rep 7: 194-207, 2014.

27. Jagani Z, Singh A, and Khosravi-Far R. FoxO tumor suppressors and BCR-ABL-induced leukemia: a matter of evasion of apoptosis. Biochim Biophys Acta 1785: 63-84, 2008.

28. Jarvis RM, Hughes SM, and Ledgerwood EC. Peroxiredoxin 1 functions as a signal peroxidase to receive, transduce, and transmit peroxide signals in mammalian cells. Free Radic Biol Med 53: 1522-1530, 2012.

29. Jiang H, Wu L, Mishra M, Chawsheen HA, and Wei Q. Expression of peroxiredoxin 1 and 4 promotes human lung cancer malignancy. Am J Cancer Res 4: 445-460, 2014.

30. Kim SY, Kim TJ, and Lee KY. A novel function of peroxiredoxin 1 (Prx-1) in apoptosis signal-regulating kinase 1 (ASK1)-mediated signaling pathway. FEBS Lett 582: 1913-1918, 2008.

31. Lehtinen MK, Yuan Z, Boag PR, Yang Y, Villen J, Becker EB, DiBacco S, de la Iglesia N, Gygi S, Blackwell TK, and Bonni A. A conserved MST-FOXO signaling pathway mediates oxidative-stress responses and extends life span. Cell 125: 987-1001, 2006.

32. Liou GY and Storz P. Reactive oxygen species in cancer. Free Radic Res 44: 479-496, 2010.

33. Madison BB, Jeganathan AN, Mizuno R, Winslow MM, Castells A, Cuatrecasas M, and Rustgi AK. Let-7 represses carcinogenesis and a stem cell phenotype in the intestine via regulation of Hmga2. PLoS Genet 11: e1005408, 2015.

34. Mishra R, Thorat D, Soundararajan G, Pradhan SJ, Chakraborty G, Lohite K, Karnik S, and Kundu GC. Semaphorin 3A upregulates FOXO 3a-dependent MelCAM expression leading to attenuation of breast tumor growth and angiogenesis. Oncogene 34: 1584-1595, 2015.

35. Morinaka A, Funato Y, Uesugi K, and Miki H. Oligomeric peroxiredoxin-I is an essential intermediate for $\mathrm{p} 53$ to activate MST1 kinase and apoptosis. Oncogene 30: 42084218, 2011.

36. Neumann CA, Cao J, and Manevich Y. Peroxiredoxin 1 and its role in cell signaling. Cell Cycle 8: 4072-4078, 2009.

37. Neumann CA and Fang Q. Are peroxiredoxins tumor suppressors? Curr Opin Pharmacol 7: 375-380, 2007.
38. Neumann CA, Krause DS, Carman CV, Das S, Devendra D, Abraham JL, Bronson RT, Fujiwara Y, Orkin SH, and Van Etten RA. Essential role for the peroxiredoxin Prdx1 in erythrocyte antioxidant defense and tumor suppression. Nature 424: 561-565, 2003.

39. This reference has been deleted.

40. Ni D, Ma X, Li HZ, Gao Y, Li XT, Zhang Y, Ai Q, Zhang P, Song EL, Huang QB, Fan Y, and Zhang X. Downregulation of FOXO3a promotes tumor metastasis and is associated with metastasis-free survival of patients with clear cell renal cell carcinoma. Clin Cancer Res 20: 1779-1790, 2014.

41. Pace PE, Peskin AV, Han MH, Hampton MB, and Winterbourn CC. Hyperoxidized peroxiredoxin 2 interacts with the protein disulfide-isomerase ERp46. Biochem $J$ 453: 475-485, 2013.

42. Paik JH, Kollipara R, Chu G, Ji H, Xiao Y, Ding Z, Miao L, Tothova Z, Horner JW, Carrasco DR, Jiang S, Gilliland DG, Chin L, Wong WH, Castrillon DH, and DePinho RA. FoxOs are lineage-restricted redundant tumor suppressors and regulate endothelial cell homeostasis. Cell 128: 309-323, 2007.

43. Panieri E and Santoro MM. ROS homeostasis and metabolism: a dangerous liason in cancer cells. Cell Death Dis 7: e2253, 2016.

44. Pelosi A, Careccia S, Sagrestani G, Nanni S, Manni I, Schinzari V, Martens JH, Farsetti A, Stunnenberg HG, Gentileschi MP, Del Bufalo D, De Maria R, Piaggio G, and Rizzo MG. Dual promoter usage as regulatory mechanism of let-7c expression in leukemic and solid tumors. Mol Cancer Res 12: 878-889, 2014.

45. Putker M, Vos HR, and Dansen TB. Intermolecular disulfide-dependent redox signalling. Biochem Soc Trans 42: 971-978, 2014.

46. Putker M, Vos HR, van Dorenmalen K, de Ruiter H, Duran AG, Snel B, Burgering BM, Vermeulen M, and Dansen TB. Evolutionary acquisition of cysteines determines FOXO paralog-specific redox signaling. Antioxid Redox Signal 22: 15-28, 2015.

47. Rahman M, Jackson LK, Johnson WE, Li DY, Bild AH, and Piccolo SR. Alternative preprocessing of RNA-sequencing data in The Cancer Genome Atlas leads to improved analysis results. Bioinformatics 31: 3666-3672, 2015.

48. Rena G, Woods YL, Prescott AR, Peggie M, Unterman TG, Williams MR, and Cohen P. Two novel phosphorylation sites on FKHR that are critical for its nuclear exclusion. EMBO J 21: 2263-2271, 2002.

49. Rhee SG. Cell signaling. $\mathrm{H}_{2} \mathrm{O}_{2}$, a necessary evil for cell signaling. Science 312: 1882-1883, 2006.

50. Rhee SG, Woo HA, Kil IS, and Bae SH. Peroxiredoxin functions as a peroxidase and a regulator and sensor of local peroxides. J Biol Chem 287: 4403-4410, 2012.

51. Roupe KM, Veerla S, Olson J, Stone EL, Sorensen OE, Hedrick SM, and Nizet V. Transcription factor binding site analysis identifies FOXO transcription factors as regulators of the cutaneous wound healing process. PLoS One 9: e89274, 2014.

52. Saleh AD, Savage JE, Cao L, Soule BP, Ly D, DeGraff W, Harris CC, Mitchell JB, and Simone NL. Cellular stress induced alterations in microRNA let-7a and let-7b expression are dependent on p53. PLoS One 6: e24429, 2011.

53. Simone NL, Soule BP, Ly D, Saleh AD, Savage JE, Degraff W, Cook J, Harris CC, Gius D, and Mitchell JB. Ionizing radiation-induced oxidative stress alters miRNA expression. PLoS One 4: e6377, 2009. 
54. Singh A, Ye M, Bucur O, Zhu S, Tanya Santos M, Rabinovitz I, Wei W, Gao D, Hahn WC, and Khosravi-Far R. Protein phosphatase 2A reactivates FOXO3a through a dynamic interplay with 14-3-3 and AKT. Mol Biol Cell 21: 1140-1152, 2010.

55. Sisci D, Maris P, Cesario MG, Anselmo W, Coroniti R, Trombino GE, Romeo F, Ferraro A, Lanzino M, Aquila S, Maggiolini M, Mauro L, Morelli C, and Ando S. The estrogen receptor alpha is the key regulator of the bifunctional role of FoxO3a transcription factor in breast cancer motility and invasiveness. Cell Cycle 12: 3405-3420, 2013.

56. Sobolesky PM, Halushka PV, Garrett-Mayer E, Smith MT, and Moussa O. Regulation of the tumor suppressor FOXO3 by the thromboxane-A2 receptors in urothelial cancer. PLoS One 9: e107530, 2014.

57. Sobotta MC, Liou W, Stocker S, Talwar D, Oehler M, Ruppert T, Scharf AN, and Dick TP. Peroxiredoxin-2 and STAT3 form a redox relay for $\mathrm{H}_{2} \mathrm{O}_{2}$ signaling. Nat Chem Biol 11: 64-70, 2015.

58. Sun QK, Zhu JY, Wang W, Lv Y, Zhou HC, Yu JH, Xu GL, Ma JL, Zhong W, and Jia WD. Diagnostic and prognostic significance of peroxiredoxin 1 expression in human hepatocellular carcinoma. Med Oncol 31: 786, 2014.

59. Tang J, Ahmad A, and Sarkar FH. The role of microRNAs in breast cancer migration, invasion and metastasis. Int $J$ Mol Sci 13: 13414-13437, 2012.

60. Thornton JE and Gregory RI. How does Lin28 let-7 control development and disease? Trends Cell Biol 22: 474-482, 2012.

61. Turner-Ivey B, Manevich Y, Schulte J, Kistner-Griffin E, Jezierska-Drutel A, Liu Y, and Neumann CA. Role for $\operatorname{Prdx} 1$ as a specific sensor in redox-regulated senescence in breast cancer. Oncogene 32: 5302-5314, 2013.

62. Tzivion G and Hay N. PI3K-AKT-FoxO axis in cancer and aging. Biochim Biophys Acta 1813: 1925, 2011.

63. van der Horst A and Burgering BM. Stressing the role of FoxO proteins in lifespan and disease. Nat Rev Mol Cell Biol 8: 440-450, 2007.

64. Wang X, Cao L, Wang Y, Wang X, Liu N, and You Y. Regulation of let-7 and its target oncogenes (Review). Oncol Lett 3: 955-960, 2012.

65. Yan L, Zhou J, Gao Y, Ghazal S, Lu L, Bellone S, Yang Y, Liu N, Zhao X, Santin AD, Taylor H, and Huang Y. Regulation of tumor cell migration and invasion by the H19/let-7 axis is antagonized by metformin-induced DNA methylation. Oncogene 34: 3076-3084, 2015.

66. Zhao B, Han H, Chen J, Zhang Z, Li S, Fang F, Zheng Q, Ma Y, Zhang J, Wu N, and Yang Y. MicroRNA let-7c inhibits migration and invasion of human non-small cell lung cancer by targeting ITGB3 and MAP4K3. Cancer Lett 342: 43-51, 2014.

67. Zhou J, Shen W, He X, Qian J, Liu S, and Yu G. Overexpression of Prdx1 in hilar cholangiocarcinoma: a pre- dictor for recurrence and prognosis. Int J Clin Exp Pathol 8: 9863-9874, 2015.

Address correspondence to:

Dr. Carola A. Neumann

Department of Pharmacology and Chemical Biology Magee Womens Research Institute University of Pittsburgh Cancer Institute 204 Craft Avenue Pittsburgh, PA 15213

E-mail: neumannc@upmc.edu

Date of first submission to ARS Central, August 28, 2016; date of final revised submission, February 16, 2017; date of acceptance, February 20, 2017.

\section{Abbreviations Used}

$\beta$-ME $=$ beta-mercaptoethanol

ASK1 = apoptosis signal-regulating kinase 1

$\mathrm{CAT}=$ catalase

$\mathrm{ChIP}=$ chromatin immunoprecipitation

co-IP $=$ coimmunoprecipitation

Cys $=$ cysteine

$\mathrm{EGFP}=$ enhanced green fluorescent protein

ERp46 $=$ endoplasmic reticulum protein 46

$\mathrm{FLAG}=$ FLAG-epitope tag

$\mathrm{FOXO}=$ forkhead box transcription factors of the $\mathrm{O}$ class

$\mathrm{HA}=$ human influenza hemagglutinin

$\mathrm{JNK}=$ Jun N-terminal kinase

$\mathrm{MEF}=$ murine embryonic fibroblast

miRNA $=$ microRNA

$\mathrm{MKP}=$ map kinase phosphatase

$\mathrm{MST}=$ mammalian sterile 20-like kinase 1

$\mathrm{NEM}=N$-ethylmaleimide

p21 = cyclin-dependent kinase inhibitor 1

p27 = cyclin-dependent kinase inhibitor1B

$\mathrm{PI} 3 \mathrm{~K}=$ phosphatidylinositol-4,5-bisphosphate 3-kinase

$\mathrm{PRDX}=$ peroxiredoxin

$\mathrm{qPCR}=$ quantitative polymerase chain reaction

$\mathrm{ROS}=$ reactive oxygen species

$\mathrm{SGK}=$ serum and glucocorticoid-regulated kinase 1

$\mathrm{sh}=$ small hairpin

SOD2 $=$ superoxide dismutase 2

STAT3 $=$ signal transducer and activator of transcription 3

$\mathrm{UTR}=$ untranslated region

$\mathrm{WT}=$ wild type 